(C) 2022, The Authors. Published by Elsevier Inc. and Fass Inc. on behalf of the American Dairy Science Association ${ }^{\circledR}$. This is an open access article under the CC BY license (http://creativecommons.org/licenses/by/4.0/).

\title{
Relationship of cow and calf circulating lipidomes with colostrum lipid composition and metabolic status of the cow
}

\author{
R. N. Klopp, ${ }^{1} \odot$ C. R. Ferreira, ${ }^{2} \odot$ T. M. Casey, ${ }^{1 *} \odot$ and J. P. Boerman ${ }^{1} \odot$ \\ ${ }^{1}$ Department of Animal Sciences, Purdue University, West Lafayette, IN 47907 \\ ${ }^{2}$ Metabolite Profiling Facility, Bindley Bioscience Center, Purdue University, West Lafayette, IN 47907
}

\begin{abstract}
Newborn calves rely on lipids in colostrum for energy and immune function. The lipid concentration in colostrum, however, is highly variable, and little is known about its composition and maternal factors that influence its composition. The first objective was to measure plasma lipid composition of multiparous cows at $35 \mathrm{~d}$ before calving (BC; $35 \pm 3 \mathrm{~d}$; \pm standard deviation) and $7 \mathrm{~d} \mathrm{BC}(7 \pm 2 \mathrm{~d})$, their colostrum, and serum lipid composition of calves (24 h after birth) using multiple reaction monitoring profiling, which is an exploratory and highly sensitive lipidomic analysis method that screens lipids based on chemical functionality. Second, data were analyzed to determine if there were relationships between circulating lipids in the cow, colostrum lipids, and calf serum lipids. Third, relationships between markers of metabolic status of the cows and circulating and colostrum lipids were analyzed with correlation analysis. Blood was sampled and plasma prepared from multiparous cows $(\mathrm{n}=16)$ at 35 and $7 \mathrm{~d}$ BC. Within $3 \mathrm{~h}$ of parturition, colostrum was collected from cows and fed to her calf. Calves received another feeding of colostrum within $12 \mathrm{~h}$ after birth and a serum sample was collected from each calf $24 \mathrm{~h}$ after the first feeding of colostrum. The metabolic status of cows was evaluated using insulin, glucose, and nonesterified fatty acid area under the curve in response to an intravenous glucose tolerance test performed at 3 wk BC. Lipids were extracted from plasma, colostrum, and calf serum and were analyzed using multiple reaction monitoring profiling. Concentration of lipids were calculated using spiked in standards and expressed as percent of lipids identified. Data were uploaded into MetaboAnalyst 5.0 for multivariate and univariate analysis. Principal component analysis indicated that circulating lipids in the cow and calf were distinct from lipids in colostrum. Phosphatidylglycerol (PG) concentration was greater
\end{abstract}

Received July 19, 2021.

Accepted October 12, 2021

*Corresponding author: theresa-casey@purdue.edu in colostrum and calf serum than in cow plasma, with 23 of the $24 \mathrm{PG}$ found in colostrum also found in calf serum. In response to intravenous glucose tolerance test in late gestation, nonesterified fatty acid area under the curve was positively related to total triacylglycerols lipids in $7 \mathrm{~d}$ BC plasma $(\mathrm{r}=0.63)$ but negatively related to total membrane lipids in colostrum $(\mathrm{r}=-0.55)$. Thus, the metabolic status of the dam influences circulating lipids and colostrum lipid content. Moreover, the circulating lipidome of the cow and calf are similar to one another and distinct from the colostrum lipidome, except for PG, where it appears that colostrum serves as the source for PG in the calf's circulation.

Key words: lipidome, colostrum, metabolic status

\section{INTRODUCTION}

Colostrum is the first secretion from the mammary glands and is an essential source of nutrients, energy, and antibodies for neonates immediately after birth. In the dairy industry, research has primarily focused on the immunoglobulin content of colostrum and the evaluation of successful passive transfer of immunity to calves. However, newborn calves rely partially on the lipids in colostrum as a source of energy to produce heat by both diet-induced thermogenesis and nonshivering thermogenesis in brown adipose tissue (Davis and Drackley, 1998). Calves are born with relatively low energy reserves, with adipose tissue making up only $3 \%$ of their birth BW (Morrill et al., 2012). Lipids also play an important role in calf immune system function. Supplementing fatty acids (FA) to calves, specifically butyrate, medium-chained fatty acids (MCFA), and linolenic acid, via milk replacer reduced inflammation, scouring, and medical treatments, while increasing antibody production (Hill et al., 2011b). Through lipolytic activity in the gastrointestinal tract, milk triacylglycerols (TG) are converted to monoglycerol and FA, which both possess antimicrobial properties (Isaacs, 2001) that aid in protecting the host against gastrointestinal pathogens and infection (Sprong et al., 2002; Yoon et al., 2018). 
The fat content of colostrum is greater on average than mature bovine milk (6.7 vs. $4.0 \%$, respectively; Godden, 2008). However, fat content in colostrum is highly variable (Kehoe et al., 2007; Morrill et al., 2012). Studies of lipid content of colostrum primarily evaluated the concentration in colostrum compared with total fat in transition milk and mature milk, with few studies evaluating lipid classes that make up colostrum (Bitman and Wood, 1990; Leiber et al., 2011; Contarini et al., 2014). Due to the vital role that colostrum plays in calf nutrition and health, the composition of lipids in colostrum needs to be further explored to enable the development of biologically relevant colostrum replacers and supplements. Moreover, there is a need for increased understanding of dairy cow physiological factors that affect colostrum composition and yield.

It is thought that colostrum formation begins 3 to 4 wk before parturition (Brandon et al., 1971), if not even earlier than 4 wk before parturition (Chandra et al., 2013). Colostrum is formed before tight junction closure between lactocytes in the mammary gland, and therefore occurs before secretory activation. Secretory activation is the onset of copious milk production (Hartmann et al., 1973), and is stimulated by the drop in circulating progesterone that occurs around parturition (Deis and Delouis, 1983; Nguyen et al., 2001). During colostrum formation, immunoglobulins and milk constituents are synthesized in lactocytes and transferred from maternal plasma into mammary secretions (Barrington et al., 2001). Fatty acids in milk are either taken up from circulating lipids or synthesized de novo in the mammary epithelial cells (Clegg et al., 2001). The current dogma is that the ability of mammary epithelial cells to synthesize FA de novo is not fully activated until secretory activation begins (Anderson et al., 2007), which occurs after parturition over a period of 24 to $48 \mathrm{~h}$ in cattle (Hartmann, 1973). Thus, the FA in colostrum are taken from circulating apolipoproteins and assembled into TG or plasma membrane lipids in the lactocytes for secretion into milk.

As dairy cattle transition from late gestation to early lactation, they experience an energy deficit, which leads to the mobilization of adipose tissue to meet energy demands. The relative amount of adipose tissue mobilization is reflected by the concentration of nonesterified fatty acids (NEFA) in circulation (McNamara, 1991). Highly elevated NEFA concentrations, which are often associated with over-conditioned cows, can lead to the development of disease in periparturient cattle (Adewuji et al., 2005; van Knegsel et al., 2005). In the first days of lactation, NEFA are used by the mammary gland to produce about $40 \%$ of milk fat (Adewuji et al., 2005), with elevated plasma NEFA concentrations related to alterations in FA composition in milk (Jorjong et al., $2014,2015)$. Therefore, the metabolic status of the cow, as indicated by NEFA concentration, is related to the lipid composition in milk (Newman and Verdin, 2017). It was surmised that because FA in colostrum are primarily derived from circulation, characterizing the lipids circulating during late gestation and the relationship of circulating and colostrum lipids to metabolic status of the cow, can increase the understanding of factors that regulate fat content of colostrum. Second, it was hypothesized that the lipidome of calf serum will be influenced by colostrum lipid composition, and therefore the circulating lipidome of the calf will be distinct from cow plasma lipidome. The first objective of this study was to measure lipidomes circulating in multiparous cows at $35 \mathrm{~d}$ before calving (BC) and $7 \mathrm{~d}$ BC, their colostrum sample, and serum samples of calves $24 \mathrm{~h}$ after birth, using the multiple reaction monitoring (MRM) profiling method. The second objective was to determine if there was a relationship between circulating lipids in the cow, colostrum, and the calf serum. The third objective was to determine if there were relationships between colostrum lipid profiles and markers of metabolic status of the cows. Wherein metabolic status was determined by response in glucose, insulin, and NEFA concentrations relative to an intravenous glucose tolerance test (IVGTT) at 2 wk before calving.

\section{MATERIALS AND METHODS}

\section{Animals and Treatments}

All procedures involving animals were reviewed and approved by the Purdue University Institutional Animal Care and Use Committee (Protocol \# 1701001523). The study was performed at the Dairy Unit of the Purdue University Animal Sciences Research and Education Center in West Lafayette, Indiana. It used 16 multiparous Holstein cows that were part of a larger study aimed at understanding the effect of exposure to chronic light-dark phase shift, which disrupts circadian clocks on metabolic status and mammary development (McCabe et al., 2021).

At $60 \mathrm{~d}$ before expected calving, milking of cows was ceased, and they were transitioned to a nonlactating diet. Cows were moved into a tiestall barn $35 \mathrm{~d}$ before expected calving, which was the start of the research trial. Cows were randomly assigned to one of 2 treatments, control (CON; $\mathrm{n}=8)$ or phase-shift $(\mathbf{P S} ; \mathrm{n}=$ 8) after being blocked by lactation number $(2.88 \pm 0.64$ vs. $2.88 \pm 0.64 ; \pm \mathrm{SD})$ and previous lactation 305 -d milk yield $(12,087 \pm 2,486$ vs. $12,467 \pm 2,497 \mathrm{~kg})$ for 
CON and PS cows, respectively. The CON cows were exposed to $16 \mathrm{~h}$ of light and $8 \mathrm{~h}$ of darkness. The PS cows were exposed to the same amount of light and dark; however, every $3 \mathrm{~d}$ there was a 6 -h shift in the light-dark cycle until the animal calved (for further details on the study design, light-dark treatments, and diets fed please refer to McCabe et al., 2021).

At approximately $5 \mathrm{~d} \mathrm{BC}$, cows were moved to box stalls in the maternity barn, where they were exposed to control light-dark cycles until calving. After parturition, calves were removed from the box stall, and bottle fed $3.79 \mathrm{~L}$ of colostrum from their dam within $3 \mathrm{~h}$ of birth. If calves did not drink all $3.79 \mathrm{~L}$, an esophageal tube was used to feed them the remaining colostrum. Calves received another $3.79 \mathrm{~L}$ of colostrum within the first $12 \mathrm{~h}$ after birth. After receiving 2 feedings of colostrum, calves were switched to $1.89 \mathrm{~L}$ of a $20 \%$ fat: $20 \%$ protein milk replacer twice daily.

\section{Sample Collection}

Blood samples were collected using a 10-mL EDTA tube (Becton Dickinson) from all cows $(\mathrm{n}=16)$ via the coccygeal vessels at $35 \pm 3 \mathrm{~d} \mathrm{BC}$ and $7 \pm 2 \mathrm{~d}$ BC. These time points were selected to profile circulating lipids in the cow before the initiation of colostrum formation and after, to identify differences potentially caused by the formation of colostrum. Samples were centrifuged within $1 \mathrm{~h}$ of collection at 4,000 $\times g$ for 15 min at $4^{\circ} \mathrm{C}$, plasma was transferred to a microcentrifuge tube, and frozen at $-20^{\circ} \mathrm{C}$ until lipid extraction. Colostrum was collected within $3 \mathrm{~h}$ of calving $(\mathrm{n}=$ 16) by milking out all 4 glands. Colostrum was either collected in the Purdue University milking parlor or by a portable milking unit that allowed for colostrum collection in maternity pens. Mode of colostrum collection was selected relative to the time of day of parturition. Specifically, if a cow calved within $2 \mathrm{~h}$ before milking time at the farm, it was collected in the parlor, otherwise it was collected using the portable milking unit. Colostrum yield was recorded by weight, and $15 \mathrm{~mL}$ of colostrum was frozen at $-20^{\circ} \mathrm{C}$ until lipid extraction. Colostrum was assessed for quality using a digital Brix refractometer (MISCO). A Brix refractometer uses the refraction of light that passes through the colostrum sample to estimate IgG concentration (Quigley et al., 2013). Colostrum fat percent was measured using the creamatocrit approach (Lucas et al., 1978), using duplicate technical replicates. Blood samples were collected from calves $24 \mathrm{~h}$ after their first colostrum feeding ( $\mathrm{n}$ $=15$ ). Blood was not collected from one calf because it received colostrum replacer instead of colostrum because its dam did not produce enough colostrum. Blood was allowed to coagulate, then centrifuged at $4,000 \times g$ for $20 \mathrm{~min}$ at $4^{\circ} \mathrm{C}$; the serum was harvested, transferred into microcentrifuge tubes, and frozen at $-20^{\circ} \mathrm{C}$ until lipid extraction.

As part of the larger project (McCabe et al., 2021), the relative metabolic state of cattle was evaluated. Biomarkers of cattle metabolic status included plasma concentrations of insulin, glucose, and NEFA area under the curve (AUC) in response to IVGTT. Blood samples were collected 14 times over $180 \mathrm{~min}$ after dosing with $250 \mathrm{mg}$ of glucose $/ \mathrm{kg}$ of BW using a $50 \%$ glucose solution at 2 ws before expected calving, which indicated relative insulin sensitivity. Blood samples were also collected from each cow at $7 \mathrm{~d}$ BC, and plasma was harvested as described above and used to measure NEFA, insulin, glucose, and BHB concentrations to estimate metabolic status of the cow at the same time the lipidome of the cow was being evaluated.

\section{Lipid Extraction and MRM Profiling}

Lipids were extracted from cow plasma taken at 35 and $7 \mathrm{~d} \mathrm{BC}$, colostrum samples, and calf serum taken $24 \mathrm{~h}$ after colostrum feeding, using the Bligh and Dyer protocol (Bligh and Dyer, 1959). The vacuum-dried lipid extracts were resuspended in $300 \mu \mathrm{L}$ of methanolchloroform (3:1) with butylated hydroxytoluene (50 $\mu \mathrm{g} / \mathrm{mL}$; stock solution). Lipid extracts from colostrum samples were further diluted 1:1,000, and plasma and serum samples were diluted 1:200 in acetonitrile: methanol:300 $\mathrm{m} M$ ammonium acetate (3:6.65:0.35). All samples were spiked with an isotopically labeled internal standard mix (IS; EquiSPLASH LIPIDOMIX, Avanti Polar Lipids) at the concentration of $0.1 \mathrm{ng} / \mu \mathrm{L}$ per IS (total of $0.8 \mathrm{ng}$ of each IS injected because $8 \mu \mathrm{L}$ of diluted lipid extract was used). An Agilent G1367A 1100 series micro-autosampler was used to deliver 8 $\mu \mathrm{L}$ of each sample, at a flow rate of $7 \mu \mathrm{L} / \mathrm{min}$, by flow injection to the ionization source of an Agilent QQQ 6410 quadrupole mass spectrometer (Agilent Technologies) for each profile analysis.

Multiple reaction monitoring profiling is a highly sensitive and exploratory lipidomic analysis method based on chemical functionality screening (Xie et al., 2021). These features of the MRM profiling method are due to the use of a triple-quadrupole mass spectrometer which can run neutral loss (NL) and precursor ion (Prec) scans. Therefore, MRM profiling is highly efficient because the sample is directly injected into the mass spectrometer without previous chromatographic separation, and a list of MRM is considered as the chemical profile of the sample. Although highly rapid and sensitive due to the use of MRM scans, lipid attribution is performed 
only at species level, which means that the lipid class, total carbon length and unsaturation level (number of double bonds) are related to each MRM. Specifically, for the TG, only one fatty acyl group attached to the glycerol backbone is identified, the other 2 are not known as the strategy is based on neutral losses expected for fatty acyl chains (Li et al., 2014). Phospholipids are categorized by their functional group, for example phosphatidylcholine is identified as the total number of carbons and unsaturated bonds across the 2 fatty acyl chains. Thus, the identity of all the fatty acyl groups in TG and plasma membrane lipids is not known, and information regarding species can only be inferred from the data.

The MRM profiling was divided into 2 different phases, a discovery and screening phase. For discovery phase, a pooled sample of all the plasma, serum, and colostrum samples was profiled. Discovery phase MRM profiling screened in pooled samples for the presence of 15 lipid classes and subclasses [phosphatidylcholine (PC), Lyso PC, sphingomyelin (SM), phosphatidylethanolamine (PE), Lyso PE, phosphatidylinositol (PI), Lyso PI, phosphatidylglycerol (PG), Lyso PG, phosphatidylserine, Lyso phosphatidylserine, TG, cholesteryl esters, acyl-carnitines, and NEFA). The letter o after PC or PG indicates the presence of an alkyl ether substituent, whereas a $\mathrm{p}$ after PC or PG indicates the presence of a 1Z-alkenyl ether (plasmalogen) substituent (i.e., PCo, PCp, PGo). The discovery phase was therefore targeted based on the Lipid Maps database (http:/ /www.lipidmaps.org/), as reported previously (de Lima et al., 2018; Dipali et al., 2019; Suarez-Trujillo et al., 2020). The discovery phase also included NL scans to screen for functional groups associated with particular lipid classes, as previously reported (de Lima et al., 2018; Dipali et al., 2019; O'Neil et al., 2020; SuarezTrujillo et al., 2020). Lipids with intensities $\geq 1$.3-fold in relation to the blank sample (injection solvent) were selected for the screening phase. The second phase of MRM profiling, or the screening phase, was performed on individual plasma, serum, and colostrum samples for MRM selected as 1.3-fold higher than the blank sample during the discovery phase. For this second phase, MRM generated during the discovery phase were divided into 3 profiling sessions, referred to as methods. They included 25 NL scans for fatty acyl residues and the MRM based on the Lipid Maps database. Dividing analysis into multiple methods enables the acquisition of robust ion signals during each 1 min MRM profiling period per sample, which is followed by a wash injection with solvent to avoid cross-contamination. Each MRM profiling method examined the samples for lipids that were related by class or functional group. Screening method 1 profiled $171 \mathrm{MRM}$ including phospho- lipids, acyl-carnitines, sphingomyelins, and cholesteryl esters (Supplemental Table S1; https://purr.purdue .edu/publications/3902/1, Klopp et al., 2021); screening method 2 profiled TG (192 MRM; Supplemental Table S2; https://purr.purdue.edu/publications/3902/ 1, Klopp et al., 2021) using MRM information from the Lipid Maps database and NL expected for FA 16:0, FA 16:1, FA 18:0, FA 18:1, FA 18:2, and FA 20:4 (Li et al., 2014); and screening method 3 profiled 200 MRM detected by NL scan during the discovery phase (Supplemental Table S3; https://purr.purdue.edu/ publications/3902/1, Klopp et al., 2021). Therefore, a total of $563 \mathrm{MRM}$ were profiled in each sample during the screening phase. Attributions of MRM are tentative and based on expected precursor ions and classdiagnostic product ions.

All MRM with an intensity 1.3-fold greater than the blank were considered for profiling data analysis. Usually, only background/baseline subtraction using manual processing or specific algorithms is performed for profiling analysis of mass spectrometry data (Zhang and Yang, 2008; Smith et al., 2014; Hao et al., 2018). The 1.3-fold threshold cut-off was based on profiling experiments that employed calibration curves and observed MRM with ion signals $30 \%$ or lower relative to the blank sample did not exhibit a linear response (Xie et al., 2021). To estimate the relative ion quantification of membrane and TG lipids, intensities of MRM were divided by the intensity of the isotopically labeled IS amount of the lipid of the same class, corrected for the amount of IS injected, and corrected for dilution rate. Estimated relative ion quantification of cholesteryl esters, campesteryl esters, and stigmasteryl esters cannot be calculated using internal standards due to source fragmentation of the lipid class. Instead, the relative ion abundances of cholesterol esters were used for the analysis.

\section{Statistics}

The current research trial was highly exploratory and conducted as part of a larger research study. Therefore, a power analysis was not conducted based on the objectives of the current trial, but rather sample size was determined based on having sufficient power based on the main objective of the larger research study. The calculated relative ion quantities or relative ion abundances, described above, were uploaded into MetaboAnalyst 5.0 (https://www.metaboanalyst.ca/). Data were normalized by autoscaling (mean-centered and divided by the SD of each variable) and Student's $t$-test was used for statistical analysis to identify MRM differentially abundant between sample types. An adjusted $P$-value $\leq 0.05$, was used to identify differentially 
Table 1. Colostrum parameters (fat concentration, Brix value, and weight) and plasma nonesterified fatty acid (NEFA), BHB, insulin, and glucose at $7 \mathrm{~d}$ before calving (BC) based on study treatments [control (CON) vs. phase shift (PS)]

\begin{tabular}{|c|c|c|c|c|}
\hline \multirow[b]{2}{*}{ Item } & \multicolumn{2}{|c|}{ Treatment } & \multirow[b]{2}{*}{ SEM } & \multirow[b]{2}{*}{$P$-value } \\
\hline & $\mathrm{CON}$ & PS & & \\
\hline \multicolumn{5}{|c|}{ Plasma at $7 \mathrm{~d} B C(\mathrm{n}=16)$} \\
\hline NEFA, mmol/L & 0.29 & 0.33 & 0.11 & 0.80 \\
\hline $\mathrm{BHB}, \mathrm{mmol} / \mathrm{L}$ & 0.71 & 0.83 & 0.06 & 0.18 \\
\hline Insulin, $\mathrm{mIU} / \mathrm{mL}$ & 0.49 & 0.45 & 0.13 & 0.86 \\
\hline Glucose, mg/dL & 78.5 & 78.0 & 2.69 & 0.90 \\
\hline \multicolumn{5}{|l|}{ Colostrum $(\mathrm{n}=16)$} \\
\hline Fat, ${ }^{1} \%$ & 5.5 & 5.5 & 0.75 & 0.99 \\
\hline Fat range, $\%$ & $0.9-8.4$ & $2.8-8.2$ & - & - \\
\hline Brix value $^{2}$ & 23.9 & 28.4 & 2.05 & 0.14 \\
\hline Brix value range & $18.3-39.1$ & $20.6-33.4$ & - & - \\
\hline Weight, kg & 8.3 & 6.7 & 1.49 & 0.46 \\
\hline Weight range, $\mathrm{kg}$ & $1.8-15.2$ & $2.6-16.9$ & - & - \\
\hline
\end{tabular}

${ }^{1}$ Fat percent was determined using the creamatocrit approach.

${ }^{2}$ Brix value was determined using a Brix refractometer.

abundant lipids. MetaboAnalyst 5.0 was used to create principal component analysis (PCA) scores plots and heatmaps to visualize the effect of treatment, day, and sample-type on MRM distribution. Supplemental data and files can be found at https://purr.purdue.edu/ publications/3902/1.

The MIXED procedure in SAS v.9.4 (SAS Institute Inc.) was used to analyze the effect of treatment in the following continuous dependent variables: colostrum fat concentration, colostrum weight, colostrum Brix value, and plasma NEFA, BHB, insulin, and glucose $7 \mathrm{~d}$ BC. Correlation analysis was also run to determine if there were linear relationships between variables of interest. The Correlation Procedure of SAS v.9.4 was used to determine correlations between lipid species (membrane and TG lipids) found in different sample types (35 BC plasma, 7 BC plasma, colostrum, and calf serum), metabolic status variables in the prepartum dairy cow (insulin AUC, glucose AUC, NEFA AUC), and colostrum fat concentration. Coefficient of correlation was set at $\geq|0.5|$, and $P$-values $\leq 0.05$ was considered significant. The current trial was highly exploratory, which is why many variables were analyzed to explore all possible relationships that may exist.

\section{RESULTS}

\section{Colostrum and Blood Parameters and Lack of an Effect of Treatment on Lipidome}

Colostrum fat concentration, as assessed by the creamatocrit approach, and IgG quantity, as assessed by Brix value, were highly variable across cows and ranged from 0.91 to $8.36 \%$ and 18.3 to 39.1 , respectively (Table 1 ). The animals used in this study were part of a larger project that analyzed the effect of prepartum circadian disruption through exposure to chronic light-dark PS versus regular $24 \mathrm{~h}$ light-dark intervals $(\mathrm{CON})$ on metabolic status and lactation performance (McCabe et al., 2021). Analysis of colostrum weight, fat and IgG quantity found no difference between PS and CON treatments. Plasma concentrations of NEFA, BHB, insulin, and glucose at $7 \mathrm{~d} \mathrm{BC}$ were also not different between treatments (all $P$-values $>0.05$ ).

The PCA scores plots indicated no separation between plasma or colostrum lipid profiles based on treatment (CON vs. PS; Supplemental Figures S1 and S2; https://purr.purdue.edu/publications/3902/1, Klopp et al., 2021). Student's $t$-test analysis found no effect of treatment $(P>0.05)$ on the quantity of individual lipids profiled in $7 \mathrm{~d} \mathrm{BC}$ plasma nor in colostrum samples. Noting that $35 \mathrm{~d}$ BC samples were collected before the start of treatment. Treatment was therefore removed from the model for all further analyses, which focused on describing the lipid profiles of plasma, serum, and colostrum and exploring potential relationships between the sample types.

\section{Distribution and Concentration of Membrane Lipids in Plasma, Serum, and Colostrum}

Principal component analysis score plots of membrane lipid classes (Figure 1A) demonstrated that calf serum and cow plasma samples clustered together and were not similar to colostrum samples. A heat map and dendrogram of hierarchical cluster analysis of membrane lipids (Figure 1B), showed the greatest distinction by sample type, with prepartum cow plasma samples clustering together and distinct from colostrum. The larger area spanned by cow plasma samples from $35 \mathrm{~d}$ 
compared with $7 \mathrm{~d} \mathrm{BC}$ in PCA plots indicated a greater degree of variation in $35 \mathrm{~d}$ BC plasma lipid content between cows (Supplemental Figure S3; https://purr .purdue.edu/publications/3902/1, Klopp et al., 2021). Student $t$-test-analysis indicated that more than half of the membrane lipid species (93 of 171) significantly decreased in abundance $(P<0.05)$ between samples from 35 and 7 d BC (Supplemental Table S4; https://purr .purdue.edu/publications/3902/1, Klopp et al., 2021).

Data were analyzed to determine the percent of membrane lipid by class (PC, PG, PI, and SM) in cow plasma, colostrum, and calf serum samples (Figure 2). The most abundant membrane lipids found in plasma at 35 and $7 \mathrm{~d}$ BC were PC, making up 84.7 and $84.3 \%$ of the total membrane lipids identified, respectively. The remaining membrane lipids detected in plasma samples at 35 and $7 \mathrm{~d}$ BC were PI, which made up 6.9 and $7.5 \%$, and SM, which made up 8.2 and $7.8 \%$ of the membrane lipids, respectively. The PG lipids were the most abundant in colostrum samples accounting for approximately $75.9 \%$ of the membrane lipids measured. Whereas PC represented $22.6 \%$ and SM $1.5 \%$ of the membrane lipids detected in colostrum, with no PI detected. The most abundant membrane lipid in calf serum was PC at $71.9 \%$, with $14.4 \% \mathrm{PG}, 7.4 \% \mathrm{PI}$ and $6.3 \% \mathrm{SM}$.

A total of 148 individual membrane lipids were analyzed for their distribution across cow plasma, colostrum and calf serum samples (Figure 3 ). There were 78 MRM related to membrane lipids shared between $35 \mathrm{~d}$ BC plasma, 7 BC plasma, colostrum, and calf serum, 58 of which were PC, and the remaining were SM. There were 44 lipids found only in plasma of cows and serum of calves, but not in colostrum, and included $32 \mathrm{PC}$, $5 \mathrm{SM}$, and $7 \mathrm{PI}$. Colostrum contained $24 \mathrm{MRM}$ with PG attribution, of which 23 were found in calf serum, whereas plasma samples from 35 and $7 \mathrm{~d}$ BC contained only one and 2, respectively. No PI were present in colostrum, but 7 species were found in cow plasma and calf serum. Cow plasma and calf serum contained 25 MRM of SM, whereas colostrum only contained 20 SM. Cholesteryl, campesteryl, and stigmasteryl esters varied between plasma, serum, and colostrum. Stigmasteryl esters were not present in colostrum, but one species was found in plasma and serum samples. There were 16 cholesteryl esters and 8 campesteryl esters species in plasma and serum samples compared with the 13 and 4 in colostrum, respectively.

Membrane lipid distribution in cow plasma, colostrum, and calf serum was also analyzed for distribution of fatty acyl carbon length and level of unsaturated bonds (Figure 4A and 5B), which represents the sum between the $2 \mathrm{FA}$ moieties. Plasma samples contained membrane lipids with the majority having 34 or 36 car- bon and 1 or 2 unsaturated bonds. The most abundant membrane lipids in colostrum by total carbon number were 32 or 34 and number of unsaturated bonds were 0 or 1 . Colostrum had a greater $(P<0.05)$ percentage of membrane lipids with 20,30 , and 32 carbons in the FA chains compared with those in the cow plasma and calf serum. Whereas cow plasma and calf serum had a greater $(P<0.05)$ percentage of $34,36,38,40$, and 42 carbons relative to colostrum. For number of unsaturated bonds, colostrum had a greater $(P<0.05)$ percentage of lipid species that were saturated, whereas plasma and serum samples had a greater $(P<0.05)$ percentage of membrane lipids with $1,2,3$, and $\geq 5$ unsaturated bonds.

The colostrum membrane lipids with less than 30 carbons in the FA chains, were all associated with PG, therefore the distribution of membrane lipids in cow plasma, colostrum, and calf serum was also analyzed without PG (Figure 4C and 5D). After removal of PG, colostrum had a greater $(P<0.05)$ percentage of membrane lipids with 30 and 32 carbons in the 2 FA chains compared with blood components, which had a greater $(P<0.05)$ percentage of $34,36,38,40$, and 42 carbons. Colostrum had a greater $(P<0.05)$ percentage of 0 and 4 unsaturated bonds across the $2 \mathrm{FA}$, whereas cow plasma and calf serum samples had a greater $(P<$ $0.05)$ percentage of mono and polyunsaturated bonds up to 3 unsaturated bonds.

The 10 most abundant membrane lipids in plasma samples made up 60 to $62 \%$ of the total membrane lipids. Nine of the 10 most abundant membrane lipids in plasma were shared between 35 and $7 \mathrm{~d}$ BC samples, all of which were PC (Table 2). Nine of the 10 most abundant membrane lipid species in colostrum were PG. The vinyl ether plasmalogen phosphatidylcholine with 32 carbons and 4 unsaturations $[\mathrm{PCp}(32: 4)]$ was the only lipid among the top 10 most abundant in colostrum shared with 35 and $7 \mathrm{~d}$ BC. Nine of the 10 most abundant MRM for membrane lipids found in calf serum were also among the most abundant found in cow plasma. Membrane lipid distribution in colostrum was also analyzed after removing PG from consideration. The 10 most abundant membrane lipids, after PG removal, were all PC. Seven of the top 10 were found in cow plasma (Table 3), with $\mathrm{PCp}(32: 4)$ making up nearly $40 \%$ of all the non-PG membrane lipids in colostrum.

\section{Distribution and Concentration of TG Lipids in Plasma, Serum, and Colostrum}

Principal component analysis of TG lipids in plasma, colostrum, and calf serum (Figure 5A) illustrated that serum and plasma samples clustered together and away 
$\mathbf{A}$
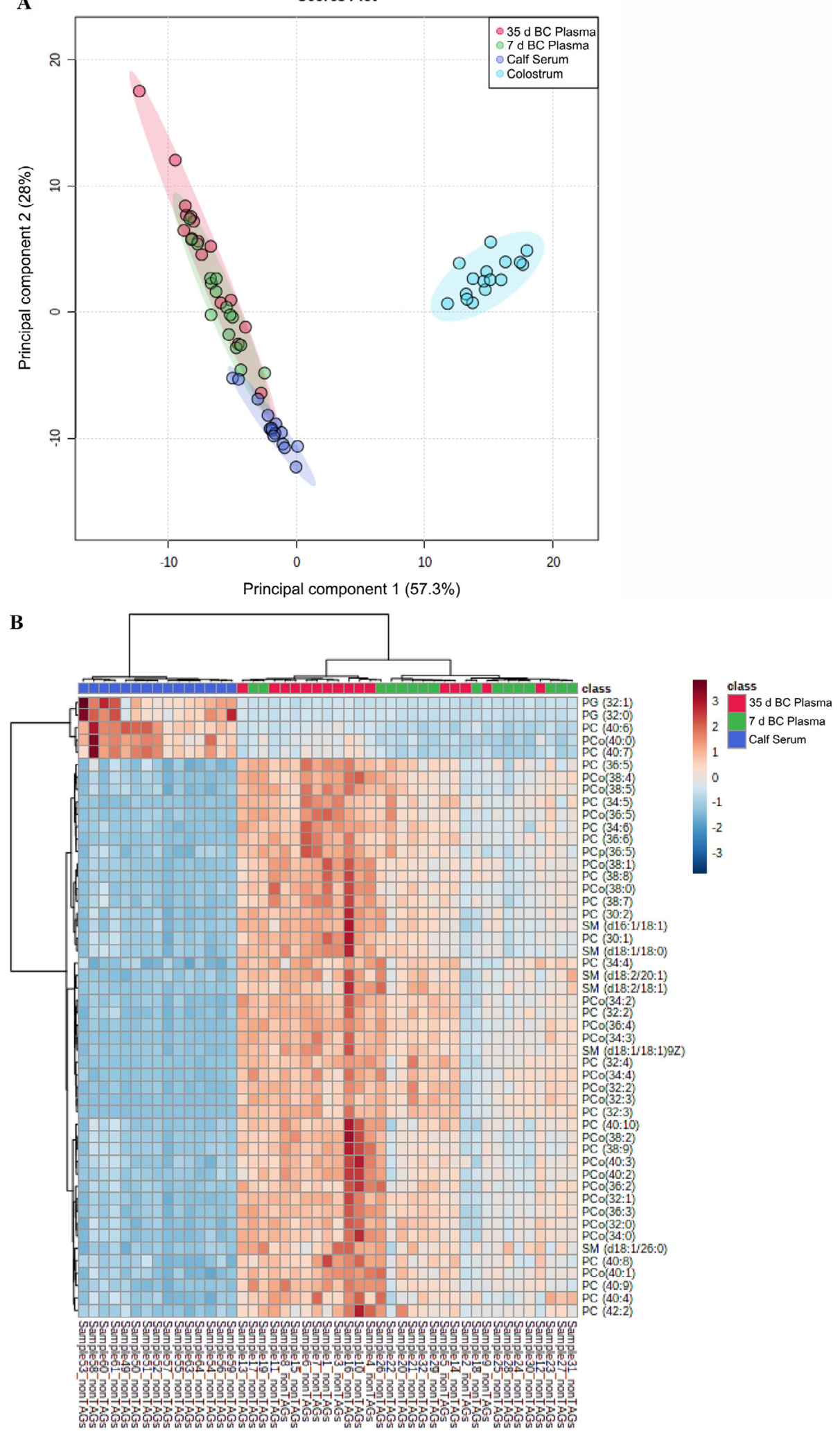

Figure 1. Principal component analysis scores plot (A) of membrane lipids in 35 d before calving (BC) plasma ( $\mathrm{n}=16)$, $7 \mathrm{~d}$ BC plasma (n $=16)$, colostrum $(\mathrm{n}=16)$, and calf serum $(\mathrm{n}=15)$ and heat map of hierarchical cluster analysis $(\mathrm{B})$ for membrane lipids in $35 \mathrm{~d}$ BC plasma ( $=16), 7 \mathrm{~d}$ BC plasma $(\mathrm{n}=16)$, and calf serum $(\mathrm{n}=15) . \mathrm{PG}=$ phosphatidylglycerol; $\mathrm{PC}=$ phosphatidylcholine; $\mathrm{PCo}=\mathrm{PC}$ with the presence of an alkyl ether substituent; $\mathrm{SM}=$ sphingomyelin. 
A

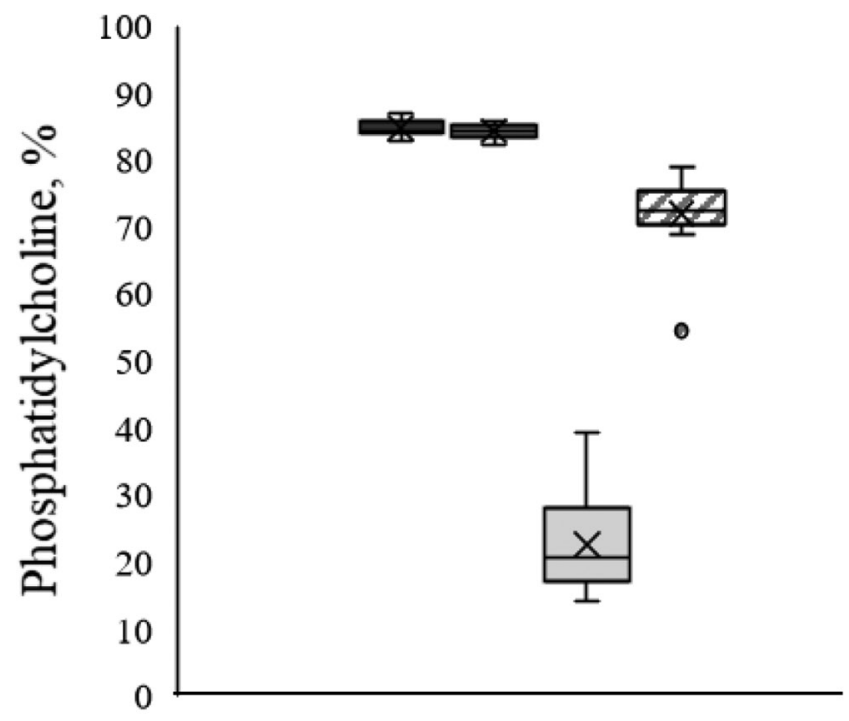

$\square 35$ BC Plasma $\square 7$ BC Plasma

Colostrum $\square$ Calf Serum

C

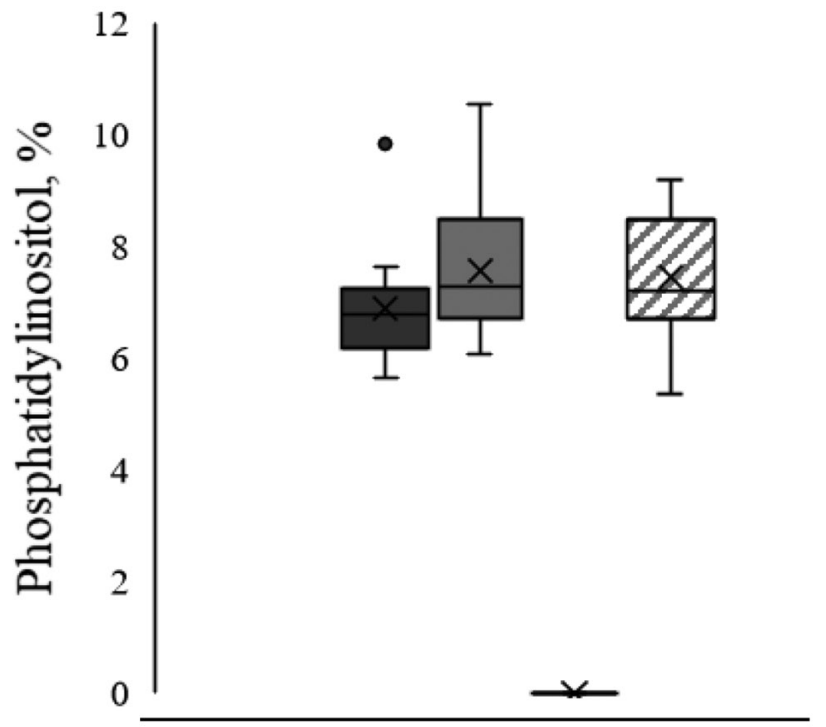

35 BC Plasma $\square 7$ BC Plasma $\square$ Colostrum $\square$ Calf Serum
B

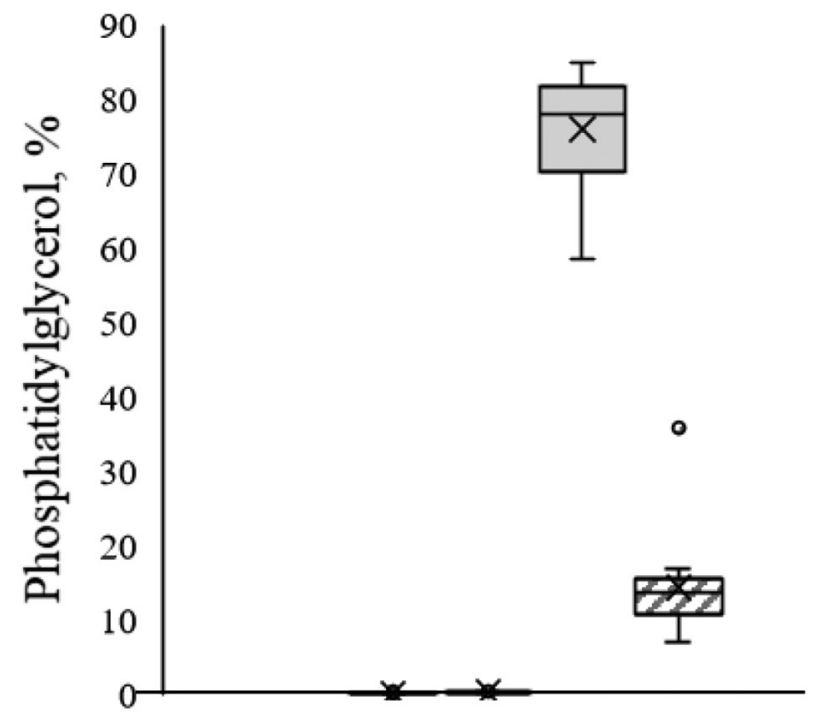

35 BC Plasma 7 BC Plasma

Colostrum $\square$ Calf Serum

D

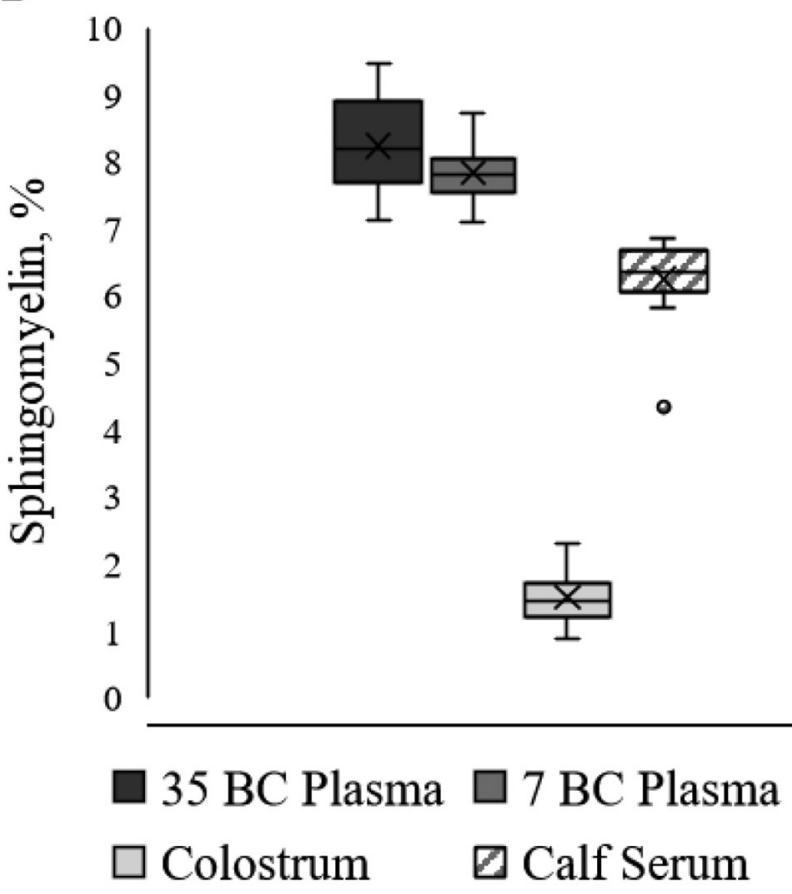

Figure 2. Membrane lipid concentration breakdown by lipid class (A: phosphatidylcholine, B: phosphatidylglycerol, C: phosphatidylinositol, and D: sphingomyelin) for cow plasma at $35 \mathrm{~d}$ before calving $(\mathrm{BC} ; \mathrm{n}=16)$ and $7 \mathrm{~d} \mathrm{BC}(\mathrm{n}=16)$, colostrum $(\mathrm{n}=16)$, and calf serum $(\mathrm{n}=15)$. Error bars represent minimum and maximum, excluding outliers.

from colostrum. To get a more detailed look at lipids circulating in cows compared with calves, colostrum was removed for hierarchical cluster analysis. Heat maps and dendrograms of hierarchical cluster analysis of TG lipids showed plasma samples clustered together and were distinct from calf serum (Figure 5B). There 


\begin{tabular}{|l|l|}
\hline PG (24:0) & PG(34:2) \\
\hline PG (24:1) & PG (36:1) \\
\hline PG (26:0) & PG (36:2) \\
\hline PG (28:0) & PG(36:3) \\
\hline PG (28:1) & PGo (20:0) \\
\hline PG (30:0) & PGo (32:0) \\
\hline PG (30:1) & PGo (34:0) \\
\hline PG(32:0) & PGo (34:1) \\
\hline PG(32:1) & PGo (36:1) \\
\hline PG (32:2) & PGp(38:6) \\
\hline
\end{tabular}

PGo (30:0)

Colostrum

PG (20:0)

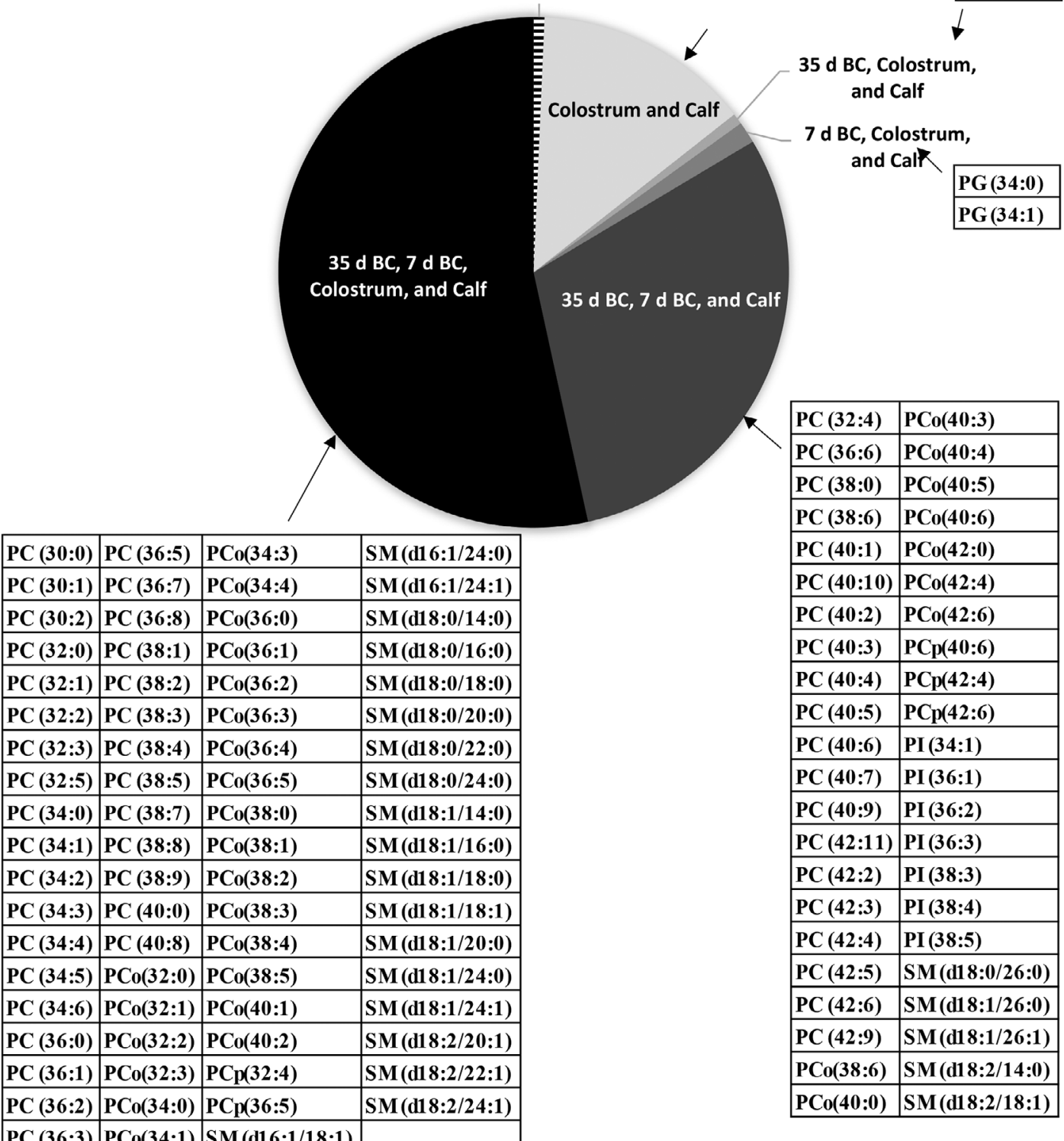

Figure 3. Pie chart summarizing membrane lipids [phosphatidylcholine (PC), phosphatidylglycerol (PG), phosphatidylinositol (PI), and sphingomyelin $(\mathrm{SM})]$ shared and distinct between $35 \mathrm{~d}$ before calving $(\mathrm{BC})$ plasma $(\mathrm{n}=16), 7 \mathrm{~d} \mathrm{BC}$ plasma $(\mathrm{n}=16)$, colostrum $(\mathrm{n}=16)$, and calf serum $(\mathrm{n}=15)$. PCo $=\mathrm{PC}$ with an alkyl ether substituent; $\mathrm{PCp}=\mathrm{PC}$ with a $1 \mathrm{Z}$-alkenyl ether substituent; $\mathrm{PGo}=\mathrm{PG}$ with an alkyl ether substituent; and PGp = PG with a 1Z-alkenyl ether substituent. 

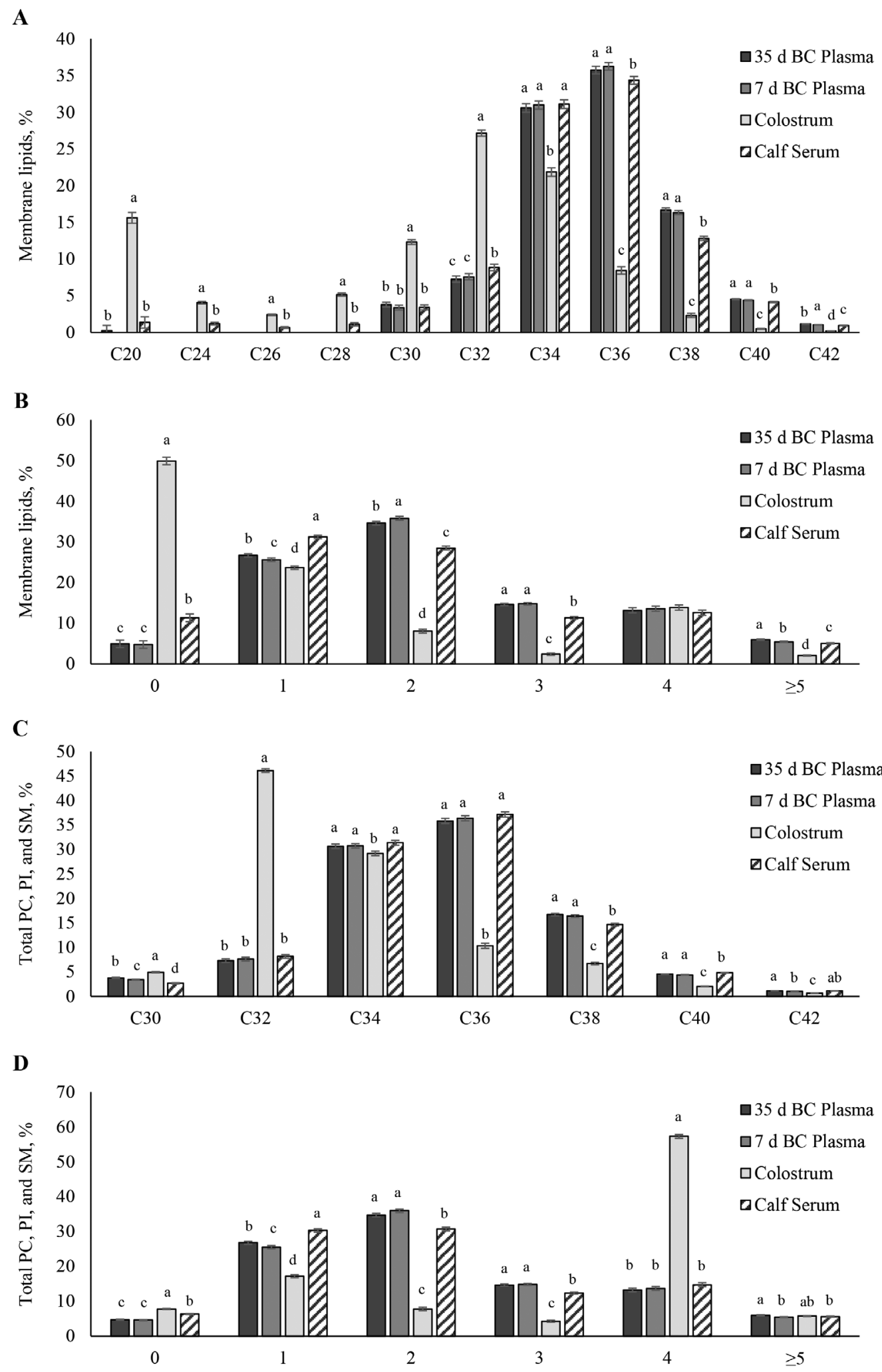

Figure 4. Concentration (LSM \pm SEM) of all identified membrane lipids [phosphatidylcholine (PC), phosphatidylglycerol (PG), phosphatidylinositol $(\mathrm{PI})$, and sphingomyelin $(\mathrm{SM})]$ based on $(\mathrm{A})$ carbon length and $(\mathrm{B})$ saturation level present in $35 \mathrm{~d}$ before calving $(\mathrm{BC})$ plasma $(\mathrm{n}=$ 16), 7 d BC plasma $(\mathrm{n}=16)$, colostrum $(\mathrm{n}=16)$, and calf serum $(\mathrm{n}=15)$ and concentration of membrane lipids after removing PG based on (C) carbon length and (D) saturation level present in $35 \mathrm{~d}$ BC plasma $(\mathrm{n}=16), 7 \mathrm{~d}$ BC plasma $(\mathrm{n}=16)$, colostrum $(\mathrm{n}=16)$, and calf serum $(\mathrm{n}=15)$. Letters $(\mathrm{a}-\mathrm{d})$ signify significant differences $(P<0.05)$ between sample types. 

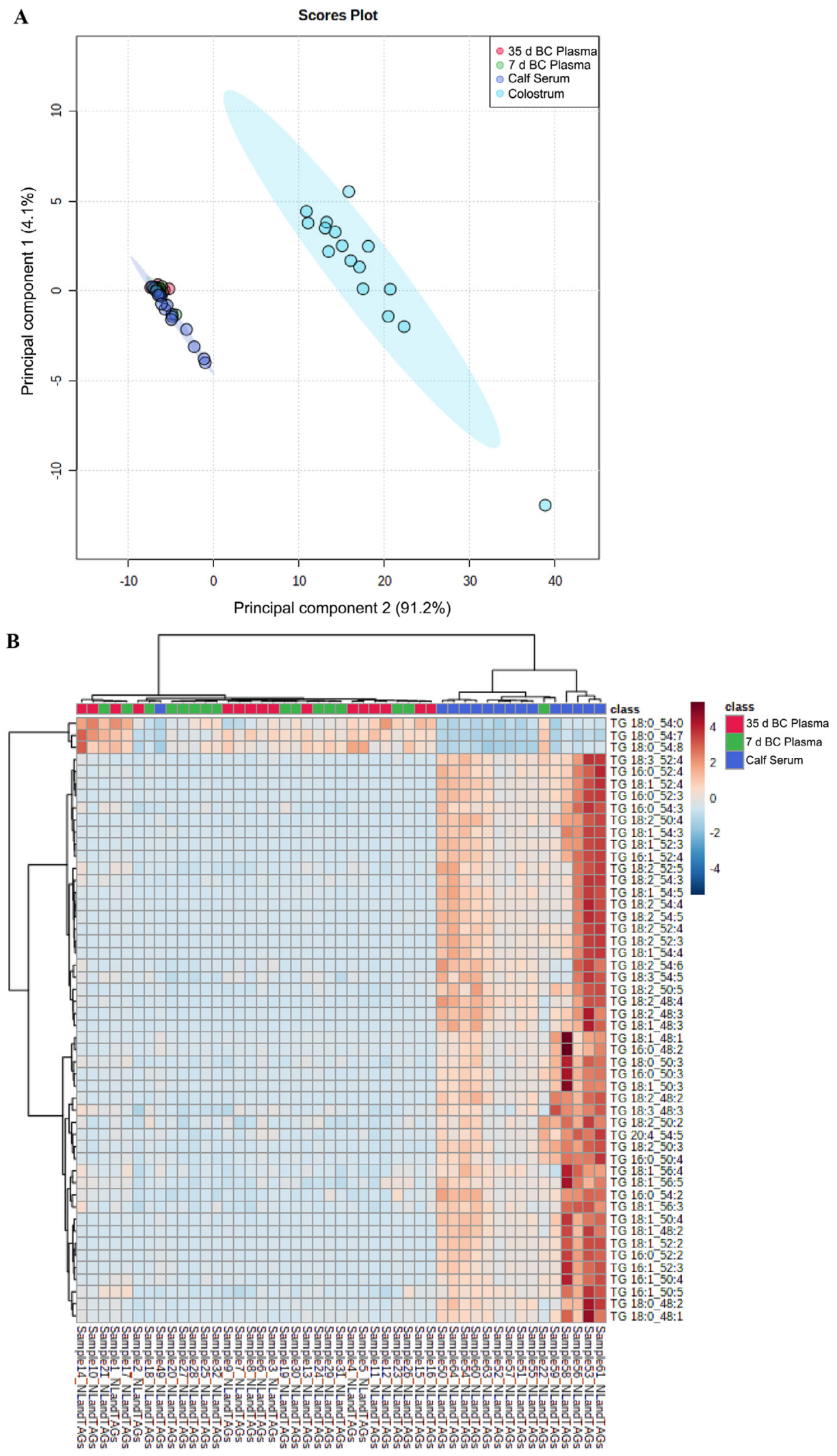

Figure 5. Principal component (PC) analysis (A) for triacylglycerol (TG) lipids in $35 \mathrm{~d}$ before calving $(\mathrm{BC})$ plasma $(\mathrm{n}=16), 7 \mathrm{~d} \mathrm{BC}$ plasma $(\mathrm{n}=16)$, colostrum $(\mathrm{n}=16)$, and calf serum $(\mathrm{n}=15)$ and heat map of hierarchical cluster analysis $(\mathrm{B})$ for TG lipids in 35 BC plasma $(\mathrm{n}=$ 16), 7 BC plasma $(\mathrm{n}=16)$, and calf serum $(\mathrm{n}=15)$. 
Table 2. Top 10 membrane lipid species [phosphatidylcholine (PC), phosphatidylglycerol (PG), phosphatidylinositol (PI), and sphingomyelin $(\mathrm{SM})$ ] and their percentage of the total membrane lipids in $35 \mathrm{~d}$ before calving $(\mathrm{BC})$ plasma $(\mathrm{n}=16), 7 \mathrm{~d} \mathrm{BC}$ plasma $(\mathrm{n}=16)$, colostrum $(\mathrm{n}$ $=16)$, and calf serum $(\mathrm{n}=15)^{1}$

\begin{tabular}{|c|c|c|c|c|c|c|c|}
\hline \multicolumn{2}{|c|}{35 d BC plasma } & \multicolumn{2}{|c|}{$7 \mathrm{~d}$ BC plasma } & \multicolumn{2}{|c|}{ Colostrum } & \multicolumn{2}{|c|}{ Calf serum } \\
\hline Lipid species & $\%$ & Lipid species & $\%$ & Lipid species & $\%$ & Lipid species & $\%$ \\
\hline PC (34:1) & 6.96 & $\mathrm{PC}(34: 1)$ & 6.87 & PCp (32:4) & 8.90 & $\mathrm{PC}(34: 2)$ & 10.14 \\
\hline PC (36:1) & 6.70 & $\mathrm{PC}(36: 1)$ & 6.54 & $P G(30: 0)$ & 8.79 & $\mathrm{PC}(36: 1)$ & 6.62 \\
\hline PC $(36: 3)$ & 4.44 & PC (36:3) & 4.49 & PG (34:1) & 7.72 & PC (36:3) & 5.42 \\
\hline PCp (32:4) & 2.94 & $\mathrm{PC}(30: 1)$ & 2.75 & PG $(28: 0)$ & 4.09 & $\mathrm{PC}(38: 4)$ & 2.12 \\
\hline $\mathrm{PC}(38: 4)$ & 2.81 & PC (38:4) & 2.65 & PG (24:0) & 3.08 & $\mathrm{PC}(36: 4)$ & 2.02 \\
\hline PC (36:4) & 2.08 & PI $(38: 4)$ & 2.29 & PG $(34: 2)$ & 2.70 & PI (38:4) & 1.98 \\
\hline
\end{tabular}

${ }^{1} \mathrm{PCp}$ indicates the presence of a 1Z-alkenyl ether (plasmalogen) substituent; PGo indicates the presence of an alkyl ether substituent.

was no significant change in TG lipid composition $(P$ $>0.05)$ between 35 and $7 \mathrm{~d} \mathrm{BC}$. The PCA showed that TG lipids in 35 and $7 \mathrm{~d}$ BC plasma were similar and closely clustered (Supplemental Figure S4; https://purr .purdue.edu/publications/3902/1, Klopp et al., 2021). Calf serum contained the greatest number of MRM for TG (127) followed by colostrum (117), 7 d BC (107) plasma, and then 35 d BC (94) plasma.

The MRM profiling information regarding TG includes the identification of one fatty acyl group, followed by total carbon number and number of unsaturated bonds across all 3 FA (Xie et al., 2021). Analysis of the distribution of TG lipids by total carbon number in the fatty acyl chains found colostrum had more TG with 48,50 , and 56 carbons $(P<0.05)$ across the $3 \mathrm{FA}$ chains compared with cow plasma at $35 \mathrm{~d} \mathrm{BC}$ and 7 d BC (Figure 6A). The number of unsaturated bonds in TG also varied by sample type. Colostrum and calf serum had more 2 and 3 unsaturated bonds across fatty

Table 3. Top 10 membrane lipid species [phosphatidylcholine (PC), phosphatidylinositol (PI), and sphingomyelin (SM), excluding phosphatidylglycerol $(\mathrm{PG})$ and their percentage of the total membrane lipids in colostrum $(\mathrm{n}=15)$

\begin{tabular}{lc}
\hline \multicolumn{2}{c}{ Colostrum (no PG) } \\
\hline Lipid species $^{1}$ & $\%$ \\
\hline PCp (32:4) & 39.93 \\
PC (34:4) & 12.10 \\
PC (34:1) & 3.68 \\
PCo (34:4) & 3.59 \\
PC (30:1) & 3.16 \\
PC (32:0) & 2.38 \\
PC (36:2) & 2.32 \\
PC (36:1) & 2.22 \\
PC (34:5) & 2.19 \\
PC (34:2) & 2.19 \\
\hline
\end{tabular}

${ }^{1} \mathrm{PCp}$ indicates the presence of a 1Z-alkenyl ether (plasmalogen) substituent; PCo indicates the presence of an alkyl ether substituent. acyl groups, than plasma, but less TG with greater than or equal to 7 unsaturated bonds than cow plasma $(P<0.05$; Figure $6 \mathrm{~B})$. The most common TG fatty acyl group for all 4 sample types was FA 18:1, followed by FA 18:0 and FA 16:0. Colostrum had greater 14:0, 16:0, and 18:1 fatty acyl groups identified as part of TG compared with plasma samples $(P<0.05$; Figure 6C). Calf serum had significantly greater FA 18:1 in TG profiled compared with plasma and colostrum $(P<$ 0.05 ). Plasma at 35 and $7 \mathrm{~d}$ BC shared 8 of the top 10 TG MRM, whereas colostrum shared 3 of these (Table 4). Colostrum shared 4 of its top 10 TG MRM with 35 d BC plasma, 5 with 7 d BC plasma, and 6 with colostrum.

\section{Correlation Analysis of Percent Fat of Colostrum and Markers of Metabolic Status with Plasma and Colostrum Lipids}

Correlation analysis was used to investigate whether there were plasma or colostrum lipids related to the variation in percent fat of colostrum. There were 7 membrane lipids (PI 36:2, PI 38:3, PI 38:4, PCo 42:0, SM d18:1/20:0, SM d18:1/18:1, and SM d16:1/22:1) in $35 \mathrm{~d}$ BC plasma that were negatively correlated $(P$ $<0.05$ ) with percent fat in colostrum (Supplemental Table S5; https://purr.purdue.edu/publications/3902/ 1, Klopp et al., 2021). In colostrum, 2 membrane lipids (PC 32:0 and SM (d18:1/18:0)) were positively correlated with colostrum fat concentration. Nine TG in $35 \mathrm{BC}$ plasma (TG 18:2_48:2, TG 16:1_52:8, TG 18:2_50:5, TG 18:2_54:5, TG 18:2_54:9, TG 18:3_50:4, TG 18:3_54:3, TG 18:2_54:10, TG 20:4_54:4) and one in 7 BC plasma (TG 16:1_52:8) were negatively correlated with percent fat in colostrum, whereas $6 \mathrm{TG}$ species in colostrum (TG 16:0_52:4, TG 18:2_50:2, TG 16:1_50:5, TG 16:1_50:3, TG 16:1_50:4, TG 18:2_52:4) 
A

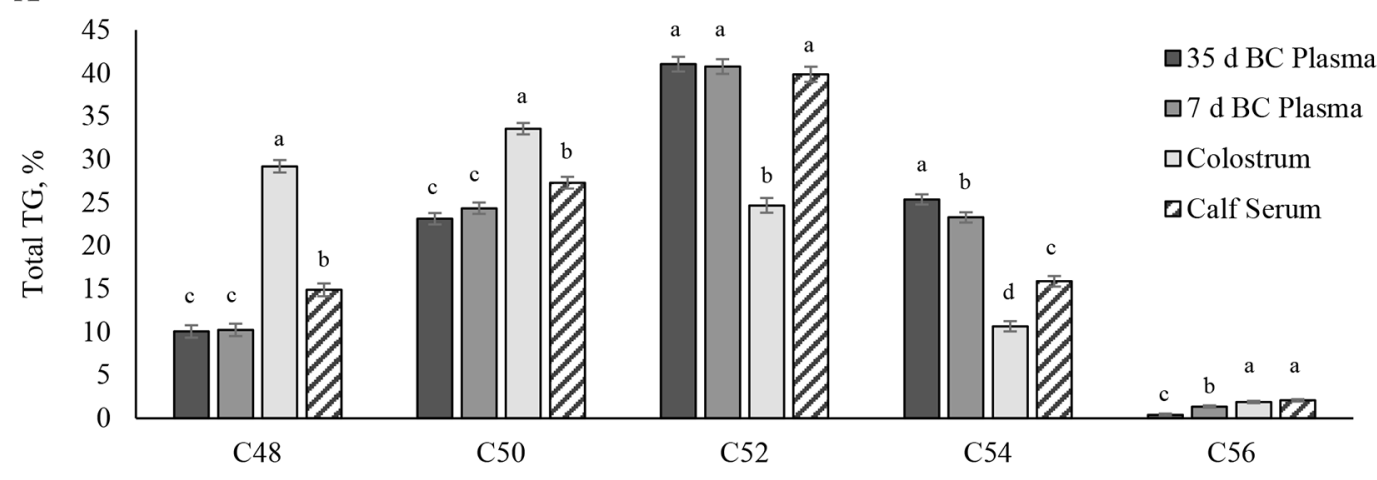

B

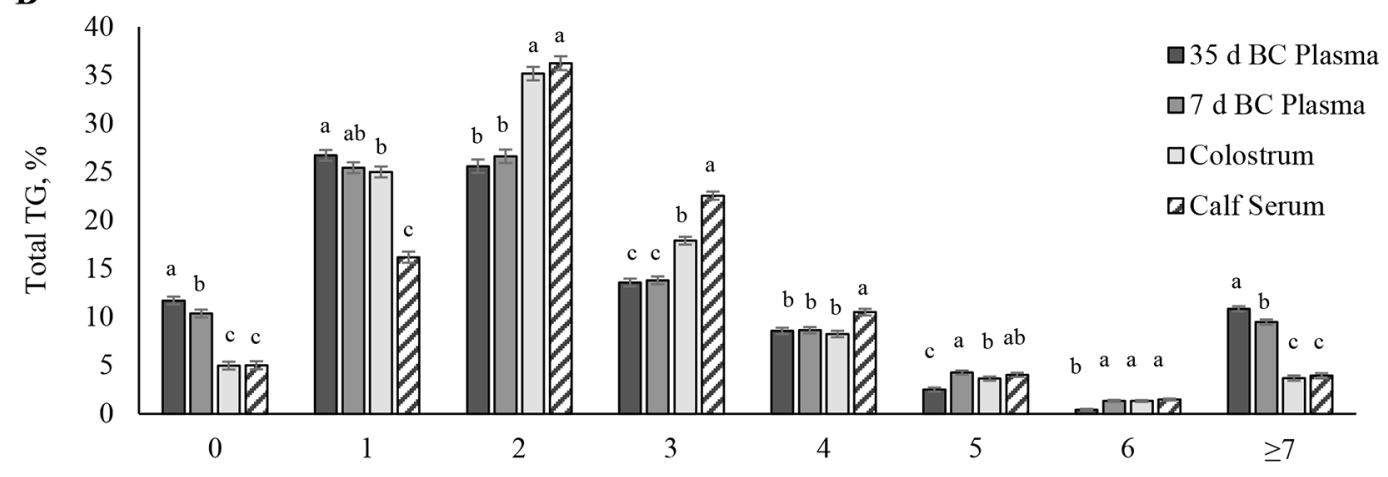

C

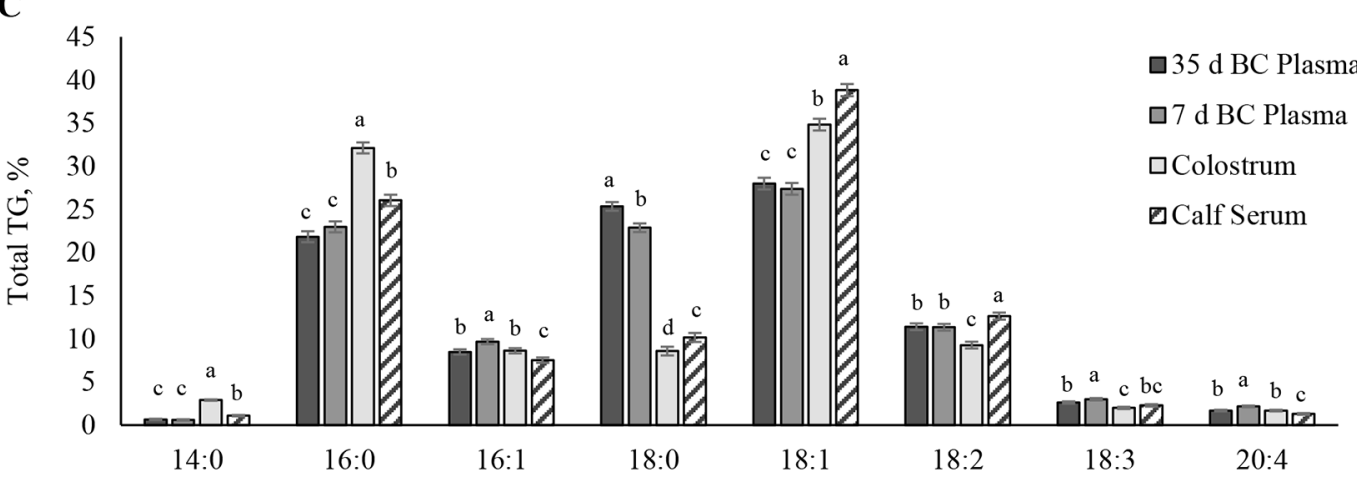

Figure 6. Concentration (LSM \pm SEM) of all identified triacylglycerol (TG) lipids based on (A) carbon length, (B) saturation level, and (C) fatty acids present in $35 \mathrm{~d}$ before calving $(\mathrm{BC})$ plasma $(\mathrm{n}=16), 7 \mathrm{~d} \mathrm{BC}$ plasma $(\mathrm{n}=16)$, colostrum $(\mathrm{n}=16)$, and calf serum $(\mathrm{n}=15)$. Letters $(\mathrm{a}-\mathrm{c})$ signify significant differences $(P<0.05)$ between sample types.

were positively correlated with fat concentration of colostrum (Supplemental Table S6; https://purr.purdue .edu/publications/3902/1, Klopp et al., 2021).

To investigate whether cow metabolic status may be responsible for colostrum variation, the relationship between markers of metabolic status and the concentration of lipids by class (i.e., membrane or TG) were analyzed. The NEFA AUC, in response to IVGTT at 2 wk prepartum, was negatively correlated with the total membrane lipid concentration of colostrum $(\mathrm{r}=$ -0.55 ; Table 5). Whereas NEFA AUC was positively correlated with total TG content of plasma samples at $7 \mathrm{~d} \mathrm{BC}(\mathrm{r}=0.63)$.

The relationships between NEFA AUC and carbon length or unsaturation level of membrane and TG lipids were analyzed (Table 5). The AUC for NEFA was positively correlated with membrane lipids in $7 \mathrm{~d} \mathrm{BC}$ plasma, with 34 carbons in the FA chains and monounsaturated FA, and negatively correlated with membrane lipids in $7 \mathrm{~d}$ BC plasma samples with 36,40 , and 44 carbons as well as 3 unsaturated bonds. The AUC for NEFA was positively correlated with membrane lipids 
Table 4. Top 10 triacylglycerol $\left(\mathrm{TG}^{1}\right)$ species and their percentage of the total TG in $35 \mathrm{~d}$ before calving $(\mathrm{BC})$ plasma $(\mathrm{n}=16), 7 \mathrm{~d} \mathrm{BC}$ plasma $(\mathrm{n}=16)$, colostrum $(\mathrm{n}=16)$, and calf serum $(\mathrm{n}=15)$

\begin{tabular}{|c|c|c|c|c|c|c|c|}
\hline \multicolumn{2}{|c|}{35 d BC plasma } & \multicolumn{2}{|c|}{$7 \mathrm{~d}$ BC plasma } & \multicolumn{2}{|c|}{ Colostrum } & \multicolumn{2}{|c|}{ Calf Serum } \\
\hline Lipid species & $\%$ & Lipid species & $\%$ & Lipid species & $\%$ & Lipid species & $\%$ \\
\hline TG $18: 0 \quad 52: 1$ & 5.34 & TG $18: 0 \quad 52: 1$ & 5.28 & TG $16: 0 \quad 48: 1$ & 7.02 & TG $16: 0 \quad 50: 2$ & 7.26 \\
\hline TG $18: 1 \_52: 2$ & 3.92 & TG $18: 1 \_52: 2$ & 4.45 & TG $18: 1 \_50: 2$ & 6.65 & TG $18: 1 \_50: 2$ & 4.71 \\
\hline TG $18: 0 \quad 52: 0$ & 3.54 & TG $16: 0 \quad 50: 2$ & 4.36 & TG $18: 1 \quad 52: 2$ & 6.06 & TG $16: 0 \quad 52: 2$ & 4.31 \\
\hline TG $16: 0 \_52: 1$ & 3.51 & TG 16:0_52:1 & 3.51 & TG $18: 1 \_48: 1$ & 5.76 & TG $18: 1 \_52: 3$ & 3.31 \\
\hline TG 18:1_50:2 & 2.36 & TG $16: 0 \_52: 2$ & 2.50 & TG 16:0_52:2 & 2.85 & TG 18:1_50:3 & 2.88 \\
\hline TG 16:0_52:0 & 2.33 & TG $18: 0 \_54: 1$ & 2.32 & TG $16: 0 \_50: 3$ & 2.74 & TG $18: 2 \_52: 3$ & 2.66 \\
\hline TG 18:1_54:2 & 2.30 & TG 16:0_48:0 & 2.02 & TG $16: 1 \_48: 1$ & 2.35 & TG 16:0_48:1 & 2.49 \\
\hline
\end{tabular}

${ }^{1}$ TG nomenclature shows 1 fatty acyl group attached to the glycerol backbone, followed by total carbon length and unsaturation level of the TG.

in colostrum that had $34,36,38,40$, and 42 carbons in the FA chains plus $1,2,3,4$, and $\geq 5$ unsaturated bonds, but negatively correlated with $24,26,28$, and 30 carbons in the FA chains as well as saturated lipid species. Circulating TG species and NEFA AUC was positively correlated with 50 carbons at $35 \mathrm{~d}$ BC, 2 unsaturated bonds at $35 \mathrm{~d} \mathrm{BC}, 50$ carbons at $7 \mathrm{~d} \mathrm{BC}$, and 2 and 3 unsaturated bonds at $7 \mathrm{~d}$ BC. The NEFA AUC was negatively correlated with TG with 3 saturated FA at $35 \mathrm{~d} \mathrm{BC}, 54$ and 56 carbons at $7 \mathrm{~d} \mathrm{BC}$, and saturated TG or those with, 5 or greater unsaturated bonds at $7 \mathrm{~d}$ BC. NEFA AUC was also negatively correlated with TG with 48 carbons and one unsaturated bond in colostrum but positively correlated with 52 carbon and 3 unsaturated bonds in colostrum. Correlation analysis between the carbon lengths and unsaturation levels of membrane lipids and TG in $35 \mathrm{~d}$ BC plasma, $7 \mathrm{~d}$ $\mathrm{BC}$ plasma, and colostrum, with glucose AUC, insulin AUC, total PG in colostrum, and colostrum fat concentration were also evaluated (Supplemental Table S7; https://purr.purdue.edu/publications/3902/1, Klopp et al., 2021).

\section{DISCUSSION}

In general, the circulating lipid profiles of cows were distinct from colostrum lipid profiles. There was a higher concentration of PG in colostrum than in circulating lipids. Plasma lipid profiles of cows were highly similar between 5 wk and one week BC and marked by similar concentrations and distributions of TG lipids between the time points. The distribution of membrane lipids in cow plasma was also similar between time points; however, approximately half of the individual membrane lipids decreased in concentration from $35 \mathrm{~d}$ $\mathrm{BC}$ to $7 \mathrm{~d} \mathrm{BC}$. The lipid profiles of cow plasma and calf serum were also similar to one another; however, calf serum contained a high concentration of PG. The high abundance of PG lipids in colostrum was related to the 20 distinct PG lipids in calf serum. Whereas plasma from multiparous cattle only had one or 2 PG lipids. This finding indicates that colostrum was potentially the source of the PG in calf serum, but cow plasma was not the source of PG in colostrum.

Lack of similarity between lipids in colostrum and those circulating in plasma likely reflects the uptake and processing of lipids by the mammary gland. In the mammary gland, lipids coming from circulation are broken down into monoacylglycerides and free FA by lipoprotein lipase in endothelial cells and then taken up by mammary epithelial cells (Bayly, 2014). Fatty acids are repackaged into TG molecules in the rough endoplasmic reticulum of mammary epithelial cells and released as fat droplets surrounded by a phospholipid monolayer. Fat droplets move to the apical membrane of the mammary epithelial cells, are encapsulated by the plasma membrane phospholipid bilayer through an apocrine process and are secreted as a milk fat globule (MFG) with a trilayer phospholipid membrane (Bauman et al., 2006). Thus, the different distribution of lipids in circulation and colostrum reflects mammary specific assembly of TG and lipid composition of the apical membrane of epithelial cells.

Despite similar distribution of classes of membrane lipids in 35 and $7 \mathrm{~d}$ BC plasma samples, approximately $50 \%$ of lipid membranes decreased from $35 \mathrm{~d}$ BC to $7 \mathrm{~d}$ BC, without a significant change in TG lipids. In order for TG and cholesterol esters to be transported through circulation, they need to be assembled into plasma lipoproteins, which consists of a hydrophobic core of TG and cholesterol esters, surrounded by a hydrophilic membrane of phospholipids apolipoproteins, and free cholesterol (Feingold and Grunfeld,, 2000). The reduction in membrane lipids with no change in TG content suggests that the apolipoprotein molecules were larger, i.e., had greater volume of TG to lipid 
Table 5. Correlations between triacylglycerol (TG) lipids in $7 \mathrm{~d}$ before calving $(\mathrm{BC})$ plasma $(\mathrm{n}=16)$, total membrane lipids in colostrum ( $\mathrm{n}$ $=16$ ), and the carbon lengths and unsaturation levels of membrane lipids and $\mathrm{TG}$ in $35 \mathrm{~d} \mathrm{BC}$ plasma $(\mathrm{n}=16), 7 \mathrm{~d} \mathrm{BC}$ plasma, and colostrum with nonesterified fatty acid (NEFA) area under the curve (AUC)

\begin{tabular}{|c|c|c|}
\hline \multirow[b]{2}{*}{ Item } & \multicolumn{2}{|c|}{ NEFA AUC } \\
\hline & r-value & $P$-value \\
\hline Total TG lipids in $7 \mathrm{~d}$ BC plasma & 0.63 & 0.01 \\
\hline Total membrane lipids in colostrum & -0.55 & 0.03 \\
\hline \multicolumn{3}{|l|}{$7 \mathrm{~d}$ BC plasma membrane lipids } \\
\hline $34 \mathrm{C}$ & 0.78 & 0.0006 \\
\hline $36 \mathrm{C}$ & -0.62 & 0.01 \\
\hline $40 \mathrm{C}$ & -0.56 & 0.03 \\
\hline $44 \mathrm{C}$ & -0.55 & 0.03 \\
\hline 1 unsaturation & 0.67 & 0.006 \\
\hline 3 unsaturations & -0.74 & 0.002 \\
\hline \multicolumn{3}{|l|}{ Colostrum membrane lipids } \\
\hline $24 \mathrm{C}$ & -0.52 & 0.05 \\
\hline $26 \mathrm{C}$ & -0.66 & 0.008 \\
\hline $28 \mathrm{C}$ & -0.66 & 0.008 \\
\hline $30 \mathrm{C}$ & -0.65 & 0.008 \\
\hline $34 \mathrm{C}$ & 0.60 & 0.02 \\
\hline $36 \mathrm{C}$ & 0.67 & 0.007 \\
\hline $38 \mathrm{C}$ & 0.67 & 0.007 \\
\hline $40 \mathrm{C}$ & 0.79 & 0.0005 \\
\hline $42 \mathrm{C}$ & 0.76 & 0.0009 \\
\hline 0 unsaturations & -0.72 & 0.003 \\
\hline 1 unsaturation & 0.53 & 0.04 \\
\hline 2 unsaturations & 0.74 & 0.002 \\
\hline 3 unsaturations & 0.58 & 0.02 \\
\hline 4 unsaturations & 0.64 & 0.01 \\
\hline$\geq 5$ unsaturations & 0.61 & 0.02 \\
\hline \multicolumn{3}{|l|}{35 d BC plasma TG lipids } \\
\hline $50 \mathrm{C}$ & 0.53 & 0.04 \\
\hline 0 unsaturations & -0.53 & 0.04 \\
\hline 2 unsaturations & 0.69 & 0.004 \\
\hline \multicolumn{3}{|l|}{7 d BC plasma } \\
\hline $50 \mathrm{C}$ & 0.78 & 0.0007 \\
\hline $54 \mathrm{C}$ & -0.73 & 0.002 \\
\hline $56 \mathrm{C}$ & -0.53 & 0.04 \\
\hline 0 unsaturations & -0.61 & 0.02 \\
\hline 2 unsaturations & 0.83 & 0.0001 \\
\hline 3 unsaturations & 0.66 & 0.008 \\
\hline 5 unsaturations & -0.57 & 0.03 \\
\hline 6 unsaturations & -0.57 & 0.03 \\
\hline$\geq 7$ unsaturations & -0.74 & 0.002 \\
\hline \multicolumn{3}{|l|}{ Colostrum TG lipids } \\
\hline $48 \mathrm{C}$ & -0.68 & 0.006 \\
\hline $52 \mathrm{C}$ & 0.69 & 0.004 \\
\hline 1 unsaturation & -0.74 & 0.002 \\
\hline 3 unsaturations & 0.63 & 0.01 \\
\hline
\end{tabular}

membrane envelope. When a cow experiences negative energy balance, which may occur during late gestation, and based on energy calculation derived from NRC (2001) 6 out of 16 cows were in negative energy balance at $7 \mathrm{BC}$ (data not shown), lipids are released from peripheral tissues as NEFA and taken up by the liver. Hepatocytes export lipids back into circulation by synthesizing and secreting very low-density lipoproteins (VLDL; Katoh, 2002). The phospholipid composition of VLDL is low compared with low-density lipoproteins and high-density lipoproteins (Stead and Welch, 1975). This would suggest that increased VLDL could explain why membrane lipids decrease from $35 \mathrm{~d}$ BC to $7 \mathrm{~d}$ $\mathrm{BC}$ as cows experience negative energy balance and are mobilizing more adipose tissue.

Cow plasma and calf serum were similar in membrane and TG lipid concentrations and distributions; however, PG was present in calf serum but not cow plasma. Colostrum had a high abundance of PG lipids. The PG lipids found in colostrum and circulating in the calf had the same number of carbons and unsaturated bonds, suggesting that when a calf consumes colostrum, PG remain intact when absorbed by enterocytes and transported into circulation. The transport of intact PG molecules may be high in neonates, as before $24 \mathrm{~h}$ postnatal (Broughton and Lecce, 1970) the tight junctions between enterocytes are not formed (Weaver et al., 2000). The high abundance of PG in colostrum may indicate its importance in mammary function or neonate requirements. Phosphatidylglycerol is a precursor for cardiolipin (CL), which is an inner mitochondrial membrane lipid (Stillwell, 2016). Therefore, the presence of $\mathrm{PG}$ in the colostrum may be reflective of lactocyte mitochondria being secreted into milk, which has been suggested in sow milk (Suarez-Trujillo et al., 2021). Because colostrum composition likely reflects the calf's requirements and mitochondria generate $90 \%$ of a cell's energy, high levels of PG substrates may be needed to support mitochondrial biogenesis in cells of growing tissues. Another potential reason for selection for PG in colostrum is its potential use by the immune system of the calf. Research in mice has shown that PG are capable of blocking toll-like receptor mediated inflammation (Choudhary et al., 2019), leading to an improved immune status and reduced energy expenditure. Additionally, as a phospholipid, the basic structure of $P G$ is a glycerol 3-phosphate backbone with FA bound to both sn- 1 and 2 . The PG in colostrum were the only membrane lipids with 20 to 28 carbons and therefore served as a source of MCFA for the calf. Calves supplemented with MCFA had improved immune status as evident by increased serum titers after vaccinating with bovine viral diarrhea and parainfluenza-3, as well as increased cytokine production, and immune cell phagocytosis capability (Hill et al., 2011a; Garcia et al., 2015) and reduced scours and treatment events (Hill et al., 2011b). Improved immune responses with MCFA supplementation may be due to their antimicrobial and antiviral effects (Zentek et al., 2011). Therefore, a source of MCFA may be important to increase immune function in newborn calves. Alternatively, PG is very abundant in bacterial membranes (Stillwell, 2016), therefore if bacteria is introduced into colostrum during colostrum collection and processing, 
these bacteria could be a source of the PG identified in colostrum samples and in calf serum.

Similar to findings of others, colostrum fat content varied greatly across cows (Quigley et al., 1994; Morrill et al., 2012). Several highly unsaturated TG species in $35 \mathrm{~d}$ BC plasma samples were negatively related to the percent fat of colostrum. The ingestion of high concentrations of PUFA coupled with an altered rumen environment causes milk fat depression in lactating cows (Bauman and Griinari, 2001). As some UFA are toxic to rumen microbes (Maia et al., 2007), they are converted to SFA in the rumen, in a process referred to as biohydrogenation. Biohydrogenation intermediates (i.e., C18:2 t-10, c-12) inhibit enzymes associated with milk fatty acid synthesis in the mammary gland resulting in reduced fat content of milk (Harvatine and Bauman, 2011). Diets that cause milk fat depression generally have increased PUFA concentrations and are associated with reduced de novo synthesis of FA in the mammary gland (Peterson et al., 2003). There is the potential that high levels of PUFA in circulation were indicative of the production of specific biohydrogenation intermediates in the rumen associated with milk fat depression. Although all of the cows were on the same diet, there is significant variation in the production of biohydrogenation intermediates for cattle fed the same diet (Calus et al., 2005).

The historical and current dogma is that FA in colostrum are obtained from circulation, as formation of colostrum is before secretory activation when de novo fatty acid synthesis is fully initiated (Anderson et al., 2007). Fatty acids with 14 carbons or less are considered de novo synthesized in the gland and derived from butyrate and acetate. Milk FA with 18 or more carbons are taken up directly from circulation. Whereas 16 carbon FA are derived either from circulation or synthesized de novo in the gland. The 2 membrane lipids in colostrum that correlated with total fat content were PC 32:0, which on average would be constituted by 2 Fsaturated 16 carbon fatty acyl groups, and SM (d18: 1/18:0), which has 218 carbon fatty acyl groups. The 6 TG in colostrum that were positively correlated with the total fat content in colostrum ranged in length from 50 to 52 carbons. Due to the carbon length of the 6 TG and the identified acyl group being 16 and 18 carbons in length, it is likely that these FA that comprise the TG are derived from circulation. These 6 TG also had a high level of unsaturated bonds across the 3 fatty acyl groups and the identified group included $\alpha$-linolenic (C18:3) and linoleic (C18:2) acids. Essential FA, and likely their derivatives (e.g., arachidonic acid C20:4) are preformed fats in colostrum. Thus, the mechanisms controlling uptake of preformed FA from circulation by the mammary gland during late gestation are affect- ing the total fat content of colostrum. That said, it is important to note that the PG in colostrum had 20 to 28 carbons across the fatty acyl groups, indicating on average these FA ranged from 10 to 14 carbons in length, and accordingly de novo synthesized. Additionally, colostrum had more membrane lipids with 30 and 32 carbons compared with blood components, which had more 34, 36, 38, 40, and 42 carbons. This also supports the idea that FA in colostrum are derived from de novo FA synthesis, despite secretory activation not being fully activated yet.

In colostrum, nearly $40 \%$ of the non-PG membrane lipids were $\mathrm{PCp}(32: 4) . \mathrm{PCp}$ is a plasmalogen, which is a naturally occurring phospholipid that has a vinyl ether fatty alcohol attached to the glycerol backbone at the $s n-1$ position (Naudí et al., 2015). Plasmalogens are commonly found in the cell membranes of electrically active tissues such as brain, heart, and myelin (Thompson et al., 2004). Also, immune cells, such as leukocytes, neutrophils, and macrophages, contain significant levels of plasmalogens (Nagan and Zoeller, 2001). The presence of $\operatorname{PCp}(32: 4)$ in colostrum would suggest that colostrum is providing the calf with cell components needed for the development of the nervous, cardiovascular, and immune system.

It is important to note, that in this study the lipid content of colostrum was evaluated by separating out the fat globules from the colostrum. The remaining colostrum fraction, however, also contains phospholipids as a part of extracellular vesicles (EV), which are small membrane-enclosed vesicles secreted from most cells and are therefore present in body fluids such as blood, urine, saliva, and milk (Ascanius et al., 2021). The specific phospholipid content of the EV present in bovine colostrum is unclear, but in bovine milk it is estimated that EV make up 35 to $40 \%$ of the phospholipids present in membrane structures (Huang and Kuksis, 1967). Therefore, it is likely that calves will end up consuming slightly more phospholipids via colostrum than just those present in the fat globules that were analyzed for this study.

The NEFA AUC was positively correlated with membrane lipids in colostrum that had 34 to 42 carbons, and 1 to $\geq 5$ unsaturated bonds, but negatively correlated with saturated membrane lipids with 24 to 30 carbons in the FA chains, which were all PG. Bovine colostrum milk fat globule membranes (MFGM) contain a greater proportion of UFA compared with the MFGM in mature bovine milk (Zou et al., 2015). This could indicate that the UFA in circulation when NEFA concentrations are high, are contributing to the UFA in the MFGM of colostrum. Moreover, high NEFA may suppress the synthesis of PG and the associated de novo synthesized MCFA in the mammary gland. Fur- 
ther work is needed to understand if less available PG is detrimental to the neonate. Also needed, is a greater understanding if high circulating NEFA is detrimental to lipid composition of colostrum, or whether altered plasma membrane lipid profiles of colostrum related to high NEFA are simply reflective of lipids available for uptake and secretion from the gland when rates of lipolysis are high in the cow.

The negative relationship of high PUFA in $35 \mathrm{~d}$ $\mathrm{BC}$ plasma with colostrum fat content may also be indicative of lipids involved in inflammatory cascades. During the transition period, when dairy cows undergo increased adipose tissue mobilization, they have an increased risk for inflammation-based diseases such as metritis, mastitis, and laminitis (Sordillo et al., 2009). In vitro studies found that treating bovine endothelial cells with NEFA increased mRNA expression of the cyclooxygenase 2 enzyme involved in eicosanoid biosynthesis, and the production of eicosanoids 9- and 13-hydroxyoctadecadienoic acids in culture (Contreras et al., 2012). Eicosanoids are components of inflammatory processes. The increased production of eicosanoids and expression of enzymes involved in eicosanoid biosynthesis when exposed to NEFA indicates that elevated NEFA concentrations are associated with the vascular inflammatory response in cattle. Eicosanoids are synthesized from PUFA and include prostaglandins and leukotrienes, which function in the induction and inhibition of inflammation (Calder, 2001). Therefore, PUFA in circulation can be used by the body to synthesize components of the immune system that lead to inflammation. There appears to be a relationship between negative energy balance, inflammation, and immunosuppression associated with disease and lower milk production (Esposito et al., 2014). Further studies are needed to understand the negative relationship of TG with highly UFA and colostrum fat content.

Additionally, NEFA AUC had relationships with total membrane and TG lipids and the carbon length and unsaturation level of membrane and TG lipids in both plasma and colostrum samples. Cows with high NEFA concentrations are at a greater risk for developing metabolic disease. Studies of humans have found high levels of NEFA are associated with dyslipidemia and development of diseases associated with metabolic syndrome (Gutierrez et al., 2009). A negative relationship was found between NEFA AUC and the total membrane lipid concentration and total PG in colostrum. The NEFA AUC was positively correlated with total TG content of plasma samples at $7 \mathrm{~d} \mathrm{BC}$. These findings would indicate that increased NEFA led to increased concentrations of TG lipids in circulation at $7 \mathrm{~d} \mathrm{BC}$ but also led to decreased membrane lipids and $\mathrm{PG}$ in colostrum. Prior research evaluating high concentrations of circulating NEFA in hyperketonemic cows reported increased milk fat (Adewuyi et al., 2005; Palmquist, 2006). When circulating NEFA is high, it leads to increased TG but potentially lower membrane lipid concentrations in plasma. This increased TG-tomembrane lipid ratio in circulating might be affecting MFG synthesis, leading to larger MFG (increased TGto-membrane lipid ratio) in colostrum, which is supported by prior research that found that NEFA has an important role in the ratio of TG to membrane lipids and therefore MFG diameter (Argov-Argaman, 2019).

\section{Limitations}

A limitation of this study was sampling protocols only captured a snapshot of what is circulating at each time point. It is unclear if the lipid species identified are coming directly from the diet, mobilized from adipose tissue, or processed by the liver. Another limitation of this study was plasma samples were prepared from the cow blood, whereas serum samples were prepared from the calves. Ideally both samples would have been plasma due to the increased reliability in lipid measurements compared with serum (Ishikawa et al., 2014). It is also important to note that the high variability in colostrum fat content from cow to cow $(n=16)$ could affect the lipidome profile analysis of the colostrum, colostrum with lower fat might have significantly less lipid species present. Lastly, this study used MRM profiling and although it is highly efficient and cost effective, it is an exploratory method and does not determine the FA composition of esterified lipid species, and so these can only be inferred from the total carbon number and level of unsaturation.

\section{CONCLUSIONS}

Lipidome analysis of colostrum found profiles distinct from the circulating lipids of the cow and calf, which were similar to each other. However, a significantly greater amount of phosphatidylglycerol was identified in the circulation of the calf compared with the cow. High levels of phosphatidylglycerol in calf serum were related to the high levels in colostrum, and were of the same species, and suggest direct transfer from the dam to the neonate through the milk. Circulating NEFA concentrations were related to lipids in circulation at $35 \mathrm{~d}$ and $7 \mathrm{~d} \mathrm{BC}$, and the lipids found in colostrum, indicating that the metabolic status of the cow can influence the lipids present in circulation and the lipids that are available to the calf in colostrum. Next steps should include determining the specific role phosphatidylglycerols play in calf health, nutritional work evaluating if altering the diet of the cow can beneficially alter the 
colostrum lipidome profile, and comparing calf blood lipidome before and after colostrum feeding.

\section{ACKNOWLEDGMENTS}

This research was funded by the Agriculture and Food Research Initiative (AFRI) grant no. 2017-67015-26569 project accession no. 1011965 from the USDA National Institute of Food and Agriculture (Washington, DC). The authors acknowledge A. Suarez-Trujillo and C. McCabe (Purdue University Department of Animal Sciences) for their dedication and contributions to this project. The authors would also like to thank M. Grott and the staff at the Animal Sciences Research and Education Center (West Lafayette, IN). The authors have not stated any conflicts of interest.

\section{REFERENCES}

Adewuyi, A. A., E. Gruys, and F. J. C. M. Van Eerdenburg. 2005. Non-esterified fatty acids (NEFA) in dairy cattle. Vet. Q. 27:117126. https://doi.org/10.1080/01652176.2005.9695192.

Anderson, S. M., M. C. Rudolph, J. L. McManaman, and M. C. Neville. 2007. Key stages in mammary gland development. Secretory activation in the mammary gland: It's not just about milk protein synthesis! Breast Cancer Res. 9:204. https://doi.org/10.1186/ bcr1653.

Argov-Argaman, N. 2019. Symposium review: Milk fat globule size: Practical implications and metabolic regulation. J. Dairy Sci. 102:2783-2795. https://doi.org/10.3168/jds.2018-15240.

Ascanius, S. R., M. S. Hansen, M. S. Ostenfeld, and J. T. Rasmussen. 2021. Milk-derived extracellular vesicles suppress inflammatory cytokine expression and nuclear factor- $\kappa \mathrm{B}$ activation in lipopolysaccharide-stimulated macrophages. Dairy. 2:165-178. https://doi .org/10.3390/dairy2020015.

Barrington, G. M., T. B. McFadden, M. T. Huyler, and T. E. Besser. 2001. Regulation of colostrogenesis in cattle. Livest. Prod. Sci. 70:95-104. https://doi.org/10.1016/S0301-6226(01)00201-9.

Bauman, D. E., and J. M. Griinari. 2001. Regulation and nutritional manipulation of milk fat: Low-fat milk syndrome. Livest. Prod. Sci. 70:15-29. https://doi.org/10.1016/S0301-6226(01)00195-6.

Bauman, D. E., I. H. Mather, R. J. Wall, and A. L. Lock. 2006. Major advances associated with the biosynthesis of milk. J. Dairy Sci. 89:1235-1243. https://doi.org/10.3168/jds.S0022-0302(06)72192 $-0$.

Bayly, G. R. 2014. Lipids and disorders of lipoprotein metabolism. Pages 702-736 in Clinical Biochemistry: Metabolic and Clinical Aspects. W. J. Marshall, M. Lapsley, A. P. Day, and R. M. Ayling, ed. Elsevier.

Bitman, J., and D. L. Wood. 1990. Changes in milk fat phospholipids during lactation. J. Dairy Sci. 73:1208-1216. https://doi.org/10 .3168/jds.S0022-0302(90)78784-X.

Bligh, E. G., and W. J. Dyer. 1959. A rapid method of total lipid extraction and purification. Can. J. Biochem. Physiol. 37:911-917. https://doi.org/10.1139/o59-099.

Brandon, M. R., D. L. Watson, and A. K. Lascelles. 1971. The mechanism of transfer of immunoglobulin into mammary secretion of cows. Aust. J. Exp. Biol. Med. Sci. 49:613-623. https://doi.org/10 $.1038 /$ icb.1971.67.

Broughton, C. W., and J. G. Lecce. 1970. Electron-microscopic studies of the jejunal epithelium from neonatal pigs fed different diets. J. Nutr. 100:445-449. https://doi.org/10.1093/jn/100.4.445.

Calder, P. C. 2001. Polyunsaturated fatty acids, inflammation, and immunity. Lipids 36:1007-1024. https://doi.org/10.1007/s11745 $-001-0812-7$.
Calus, M. P. L., M. J. Carrick, R. F. Veerkamp, and M. E. Goddard. 2005. Estimation of genetic parameters for milk fat depression in dairy cattle. J. Dairy Sci. 88:1166-1177. https://doi.org/10.3168/ jds.S0022-0302(05)72783-1.

Chandra, G., A. Aggarwal, A. K. Singh, M. Kumar, and R. C. Upadhyay. 2013. Effect of vitamin $\mathrm{E}$ and zinc supplementation on energy metabolites, lipid peroxidation, and milk production in peripartum sahiwal cows. Asian-Australas. J. Anim. Sci. 26:1569-1576. https://doi.org/10.5713/ajas.2012.12682.

Choudhary, V., R. Uaratanawong, R. R. Patel, H. Patel, W. Bao, B. Hartney, E. Cohen, X. Chen, Q. Zhong, C. M. Isales, and W. B. Bollag. 2019. Phosphatidylglycerol inhibits toll-like receptor-mediated inflammation by danger-associated molecular patterns. J. Invest. Dermatol. 139:868-877. https://doi.org/10.1016/j.jid.2018 .10 .021 .

Clegg, R. A., M. C. Barber, L. Pooley, I. Ernens, Y. Larondelle, and M. T. Travers. 2001. Milk fat synthesis and secretion: Molecular and cellular aspects. Livest. Prod. Sci. 70:3-14. https://doi.org/10 .1016/S0301-6226(01)00194-4.

Contarini, G., M. Povolo, V. Pelizzola, L. Monti, A. Bruni, L. Passolungo, F. Abeni, and L. Degano. 2014. Bovine colostrum: Changes in lipid constituents in the first 5 days after parturition. J. Dairy Sci. 97:5065-5072. https://doi.org/10.3168/jds.2013-7517.

Contreras, G. A., W. Raphael, S. A. Mattmiller, J. Gandy, and L. M. Sordillo. 2012. Nonesterified fatty acids modify inflammatory response and eicosanoid biosynthesis in bovine endothelial cells. J. Dairy Sci. 95:5011-5023. https://doi.org/10.3168/jds.2012-5382.

Davis, C. L., and J. K. Drackley. 1998. The Development, Nutrition, and Management of the Young Calf. First ed. Iowa State University Press.

de Lima, C. B., C. R. Ferreira, M. P. Milazzotto, T. J. P. Sobreira, A. A. Vireque, and R. G. Cooks. 2018. Comprehensive lipid profiling of early stage oocytes and embryos by MRM profiling. J. Mass Spectrom. 53:1247-1252. https://doi.org/10.1002/jms.4301.

Deis, R. P., and C. Delouis. 1983. Lactogenesis induced by ovariectomy in pregnant rats and its regulation by oestrogen and progesterone. J. Steroid Biochem. 18:687-690. https://doi.org/10.1016/0022 $-4731(83) 90246-7$.

Dipali, S. S., C. R. Ferreira, L. T. Zhou, M. T. Pritchard, and F. E. Duncan. 2019. Histologic analysis and lipid profiling reveal reproductive age-associated changes in peri-ovarian adipose tissue. Reprod. Biol. Endocrinol. 17:46. https://doi.org/10.1186/s12958 -019-0487-6.

Esposito, G., P. C. Irons, E. C. Webb, and A. Chapwanya. 2014. Interactions between negative energy balance, metabolic diseases, uterine health and immune response in transition dairy cows. Anim. Reprod. Sci. 144:60-71. https://doi.org/10.1016/j.anireprosci.2013 .11.007.

Feingold, K. R., and C. Grunfeld. 2000. Introduction to Lipids and Lipoproteins. MDText.com Inc.

Garcia, M., J. H. Shin, A. Schlaefli, L. F. Greco, F. P. Maunsell, J. E. P. Santos, C. R. Staples, and W. Thatcher. 2015. Increasing intake of essential fatty acids from milk replacer benefits performance, immune responses, and health of preweaned Holstein calves. J. Dairy Sci. 98:458-477. https://doi.org/10.3168/jds.2014-8384.

Godden, S. 2008. Colostrum management for dairy calves. Vet. Clin. North Am. Food Anim. Pract. 24:19-39. https://doi.org/10.1016/ j.cvfa.2007.10.005.

Gutierrez, D. A., M. J. Puglisi, and A. H. Hasty. 2009. Impact of increased adipose tissue mass on inflammation, insulin resistance, and dyslipidemia. Curr. Diab. Rep. 9:26-32. https://doi.org/10 .1007/s11892-009-0006-9.

Hao, L., J. Wang, D. Page, S. Asthana, H. Zetterberg, C. Carlsson, O. C. Okonkwo, and L. Li. 2018. Comparative evaluation of MSbased metabolomics software and its application to preclinical Alzheimer's disease. Sci. Rep. 8:9291. https://doi.org/10.1038/ s41598-018-27031-x.

Hartmann, P. E. 1973. Changes in the composition and yield of the mammary secretion of cows during the initiation of lactation. J. Endocrinol. 59:231-247. https://doi.org/10.1677/joe.0.0590231. 
Hartmann, P., P. Trevethan, and J. Shelton. 1973. Progesterone and oestrogen and the initiation of lactation in ewes. J. Endocrinol. 59:249-259. https://doi.org/10.1677/joe.0.0590249.

Harvatine, K. J., and D. E. Bauman. 2011. Characterization of the acute lactational response to trans-10, cis-12 conjugated linoleic acid. J. Dairy Sci. 94:6047-6056. https://doi.org/10.3168/jds.2011 -4657 .

Hill, T. M., H. G. Bateman II, J. M. Aldrich, and R. L. Schlotterbeck. 2011a. Effect of various fatty acids on dairy calf performance. Prof. Anim. Sci. 27:167-175. https://doi.org/10.15232/ S1080-7446(15)30470-8.

Hill, T. M., M. J. VandeHaar, L. M. Sordillo, D. R. Catherman, H. G. Bateman II, and R. L. Schlotterbeck. 2011b. Fatty acid intake alters growth and immunity in milk-fed calves. J. Dairy Sci. 94:3936-3948. https://doi.org/10.3168/jds.2010-3935.

Huang, T. C., and A. Kuksis. 1967. A comparative study of the lipids of globule membrane and fat core and of the milk serum of cows. Lipids 2:453-460. https://doi.org/10.1007/BF02533171.

Isaacs, C. E. 2001. The antimicrobial function of milk lipids. Adv. Nutr. Res. 10:271-285.

Ishikawa, M., K. Maekawa, K. Saito, Y. Senoo, M. Urata, M. Murayama, Y. Tajima, Y. Kumagai, and Y. Saito. 2014. Plasma and serum lipidomics of healthy white adults shows characteristic profiles by subjects' gender and age. PLoS One 9:e91806. https://doi .org/10.1371/journal.pone.0091806.

Jorjong, S., A. T. M. Van Knegsel, J. Verwaeren, R. M. Bruckmaier, B. De Baets, B. Kemp, and V. Fievez. 2015. Milk fatty acids as possible biomarkers to diagnose hyperketonemia in early lactation. J. Dairy Sci. 98:5211-5221. https://doi.org/10.3168/jds.2014 $-8728$

Jorjong, S., A. T. M. Van Knegsel, J. Verwaeren, M. V. Lahoz, R. M. Bruckmaier, B. De Baets, B. Kemp, and V. Fievez. 2014. Milk fatty acids as possible biomarkers to early diagnose elevated concentrations of blood plasma nonesterified fatty acids in dairy cows. J. Dairy Sci. 97:7054-7064. https://doi.org/10.3168/jds.2014-8039.

Katoh, N. 2002. Relevance of apolipoproteins in the development of fatty liver and fatty liver-related peripartum diseases in dairy cows. J. Vet. Med. Sci. 64:293-307. https://doi.org/10.1292/jvms .64 .293 .

Kehoe, S. I., B. M. Jayarao, and A. J. Heinrichs. 2007. A survey of bovine colostrum composition and colostrum management practices on Pennsylvania dairy farms. J. Dairy Sci. 90:4108-4116. https:// doi.org/10.3168/jds.2007-0040.

Klopp, R. N., C. R. Ferreira, T. M. Casey, and J. P. Boerman. 2021. Relationship of cow and calf circulating lipidomes with colostrum lipid composition and metabolic status of the cow. Purdue University Research Repository https://doi.org/10.4231/7DT2-8D82.

Leiber, F., R. Hochstrasser, H. R. Wettstein, and M. Kreuzer. 2011. Feeding transition cows with oilseeds: Effects on fatty acid composition of adipose tissue, colostrum and milk. Livest. Sci. 138:1-12. https://doi.org/10.1016/j.livsci.2010.11.016.

Li, M., E. Butka, and X. Wang. 2014. Comprehensive quantification of triacylglycerols in soybean seeds by electrospray ionization mass spectrometry with multiple neutral loss scans. Sci. Rep. 4:6581. https://doi.org/10.1038/srep06581

Lucas, A., J. A. Gibbs, R. L. Lyster, and J. D. Baum. 1978. Creamatocrit: Simple clinical technique for estimating fat concentration and energy value of human milk. Br. Med. J. 1:1018-1020. https://doi .org/10.1136/bmj.1.6119.1018.

Maia, M. R. G., L. C. Chaudhary, L. Figueres, and R. J. Wallace. 2007. Metabolism of polyunsaturated fatty acids and their toxicity to the microflora of the rumen. Antonie van Leeuwenhoek 91:303-314. https://doi.org/10.1007/s10482-006-9118-2.

McCabe, C. J., A. Suarez-Trujillo, K. A. Teeple, T. M. Casey, and J. P. Boerman. 2021. Chronic prepartum light-dark phase shifts in cattle disrupt circadian clocks, decrease insulin sensitivity and mammary development, and are associated with lower milk yield through 60 days postpartum. J. Dairy Sci. 104:2422-2437. https:/ /doi.org/10.3168/jds.2020-19250.
McNamara, J. P. 1991. Regulation of adipose tissue metabolism in support of lactation. J. Dairy Sci. 74:706-719. https://doi.org/10 .3168/jds.S0022-0302(91)78217-9.

Morrill, K. M., E. Conrad, A. Lago, J. Campbell, J. Quigley, and H. Tyler. 2012. Nationwide evaluation of quality and composition of colostrum on dairy farms in the United States. J. Dairy Sci. 95:3997-4005. https://doi.org/10.3168/jds.2011-5174.

Nagan, N., and R. A. Zoeller. 2001. Plasmalogens: Biosynthesis and functions. Prog. Lipid Res. 40:199-229. https://doi.org/10.1016/ S0163-7827(01)00003-0.

Naudí, A., R. Cabré, M. Jové, V. Ayala, H. Gonzalo, M. PorteroOtín, I. Ferrer, and R. Pamplona. 2015. Lipidomics of human brain aging and Alzheimer's disease pathology. Int. Rev. Neurobiol. 122:133-189. https://doi.org/10.1016/bs.irn.2015.05.008.

Newman, J. C., and E. Verdin. 2017. B-hydroxybutyrate: A signaling metabolite. Annu. Rev. Nutr. 37:51-76.

Nguyen, D. A., A. F. Parlow, and M. C. Neville. 2001. Hormonal regulation of tight junction closure in the mouse mammary epithelium during the transition from pregnancy to lactation. J. Endocrinol. 170:347-356. https://doi.org/10.1677/joe.0.1700347.

NRC (National Research Council). 2001. Nutrient Requirements of Dairy Cattle. 7th revised edition. National Academy Press.

O'Neil, E. V., G. W. Burns, C. R. Ferreira, and T. E. Spencer. 2020. Characterization and regulation of extracellular vesicles in the lumen of the ovine uterus. Biol. Reprod. 102:1020-1032. https://doi .org/10.1093/biolre/ioaa019.

Palmquist, D. L. 2006. Milk fat: Origin of fatty acids and influence of nutritional factors thereon. Pages 43-92 in Advanced Dairy Chemistry, Volume 2: Lipids. 3rd ed. P. F. Fox and P. L. H. McSweeney, ed. Springer US.

Peterson, D. G., E. A. Matitashvili, and D. E. Bauman. 2003. Diet-induced milk fat depression in dairy cows results in increased trans-10, cis-12 CLA in milk fat and coordinate suppression of mRNA abundance for mammary enzymes involved in milk fat synthesis. J. Nutr. 133:3098-3102. https://doi.org/10.1093/jn/133.10 .3098 .

Quigley, J. D. III, K. R. Martin, H. H. Dowlen, L. B. Wallis, and K. Lamar. 1994. Immunoglobulin concentration, specific gravity, and nitrogen fractions of colostrum from Jersey cattle. J. Dairy Sci. 77:264-269. https://doi.org/10.3168/jds.S0022-0302(94)76950-2.

Quigley, J. D., A. Lago, C. Chapman, P. Erickson, and J. Polo. 2013. Evaluation of the Brix refractometer to estimate immunoglobulin G concentration in bovine colostrum. J. Dairy Sci. 96:1148-1155. https://doi.org/10.3168/jds.2012-5823.

Smith, R. A. D. Mathis, D. Ventura, and J. T. Prince. 2014. Proteomics, lipidomics, metabolomics: A mass spectrometry tutorial from a computer scientist's point of view. BMC Bioinformatics 15(Suppl 7):S9. https://doi.org/10.1186/1471-2105-15-S7-S9.

Sordillo, L. M., G. A. Contreras, and S. L. Aitken. 2009. Metabolic factors affecting the inflammatory response of periparturient dairy cows. Anim. Health Res. Rev. 10:53-63. https://doi.org/10.1017/ S1466252309990016.

Sprong, R. C., M. F. E. Hulstein, and R. van der Meer. 2002. Bovine milk fat components inhibit food-borne pathogens. Int. Dairy J. 12:209-215. https://doi.org/10.1016/S0958-6946(01)00139-X.

Stead, D., and V. A. Welch. 1975. Lipid composition of bovine serum lipoproteins. J. Dairy Sci. 58:122-127. https://doi.org/10.3168/jds .S0022-0302(75)84528-0.

Stillwell, W. 2016. An Introduction to Biological Membranes: Composition, Structure and Function. 2nd ed. Elsevier.

Suarez-Trujillo, A., K. Huff, C. Ramires Ferreira, T. J. Paschoal Sobreira, K. K. Buhman, and T. Casey. 2020. High-fat-diet induced obesity increases the proportion of linoleic acyl residues in dam serum and milk and in suckling neonate circulation. Biol. Reprod. 103:736-749. https://doi.org/10.1093/biolre/ioaa103.

Suarez-Trujillo, A., S. M. Luecke, L. Logan, C. Bradshaw, K. R. Stewart, R. C. Minor, C. Ramires Ferreira, and T. M. Casey. 2021 Changes in sow milk lipidome across lactation occur in fatty acyl residues of triacylglycerol and phosphatidylglycerol lipids, but not 
in plasma membrane phospholipids. Animal 15:100280. https:// doi.org/10.1016/j.animal.2021.100280.

Thompson, D. H., J. Shin, J. Boomer, and J. Kim. 2004. Preparation of plasmenylcholine lipids and plasmenyl-type liposome dispersions. Methods Enzymol. 387:153-168. https://doi.org/10.1016/ S0076-6879(04)87010-1.

van Knegsel, A. T. M., H. van den Brand, J. Dijkstra, S. Tamminga, and B. Kemp. 2005. Effect of dietary energy source on energy balance, production, metabolic disorders and reproduction in lactating dairy cattle. Reprod. Nutr. Dev. 45:665-688. https://doi.org/ 10.1051/rnd:2005059.

Weaver, D. M., J. W. Tyler, D. C. VanMetre, D. E. Hostetler, and G. M. Barrington. 2000. Passive transfer of colostral immunoglobulins in calves. J. Vet. Intern. Med. 14:569-577. https://doi.org/10 $.1111 / j .1939-1676.2000 . t b 02278 . x$.

Xie, Z., C. R. Ferreira, A. A. Virequ, and R. G. Cooks. 2021. Multiple reaction monitoring profiling (MRM profiling): Small molecule exploratory analysis guided by chemical functionality. Chem. Phys. Lipids 235:105048. https://doi.org/10.1016/j.chemphyslip.2021 .105048 .

Yoon, B. K., J. A. Jackman, E. R. Valle-González, and N. J. Cho. 2018. Antibacterial free fatty acids and monoglycerides: Biological activities, experimental testing, and therapeutic applications. Int. J. Mol. Sci. 19:1114. https://doi.org/10.3390/ijms19041114.
Zentek, J., S. Buchheit-Renko, F. Ferrara, W. Vahjen, A. G. Van Kessel, and R. Pieper. 2011. Nutritional and physiological role of medium-chain triglycerides and medium-chain fatty acids in piglets. Anim. Health Res. Rev. 12:83-93. https://doi.org/10.1017/ S1466252311000089.

Zhang, H., and Y. Yang. 2008. An algorithm for thorough background subtraction from high-resolution LC/MS data: Application for detection of glutathione-trapped reactive metabolites. J. Mass Spectrom. 43:1181-1190. https://doi.org/10.1002/jms.1390.

Zou, X., Z. Guo, Q. Jin, J. Huang, L. Cheong, X. Xu, and X. Wang. 2015. Composition and microstructure of colostrum and mature bovine milk fat globule membrane. Food Chem. 185:362-370. https://doi.org/10.1016/j.foodchem.2015.03.145.

\section{ORCIDS}

R. N. Klopp @ https://orcid.org/0000-0001-8485-6831

C. R. Ferreira ๑ https://orcid.org/0000-0003-3988-6454

T. M. Casey $\odot$ https://orcid.org/0000-0002-8835-3550

J. P. Boerman (ㄴ https://orcid.org/0000-0002-0336-8295 